\title{
No solo causalidad en el mundo físico: ontología y metodología pseudocausal ${ }^{*}$
}

\section{Wilfredo Quezada P.**}

Luis Pavez F.*** $^{* *}$

\begin{abstract}
Resumen
En este trabajo mostramos que ciertas tesis sobre pseudoprocesos causales, procesos cuya característica prominente parece ser superar la velocidad de la luz, y que han sido defendidas por autores trabajando en causalidad física, deben ser cuestionadas o seriamente modificadas. Para cumplir nuestro propósito, mostraremos, en primer lugar, cómo modelar por igual pseudoprocesos y timewise gerrymanders en relatividad especial. En segundo lugar, argumentaremos que hay una sola categoría de no-entidades causales y que no hay nada en la relatividad que parezca justificar el apelar a una diferencia ontológica basada en geinidentidad a través del tiempo. Esto nos habilitará, a su vez, a proponer una definición más precisa de un pseudoproceso que aquella presupuesta en la literatura examinada. En tercer lugar, mostraremos en detalle cómo dichos procesos, entendidos de la manera que aquí proponemos, son y han sido herramientas metodológicas de un valor indudable cuando se desea estudiar - a través de procedimientos de medición usuales- relaciones causales efectivas que se sostienen en el mundo físico. Finalmente, conectaremos nuestras conclusiones con la crítica sobre la relación entre causalidad ordinaria y procesos físicos gobernados por ecuaciones que ha defendido R. Torretti y mostraremos que, aunque podemos permanecer teóricamente neutros sobre su con-

\footnotetext{
* Recibido: octubre 2016.

** Departamento de Filosofía, Universidad de Santiago de Chile (USACH) / Instituto de Filosofía, Universidad de Valparaíso, Chile (UV). Santiago, Chile. Email: wilfredo.quezada@usach.cl

*** Departamento de Filosofía, Universidad de Santiago de Chile (USACH). Santiago, Chile. Email: pavezfloresluis@gmail.com
} 
cepción antropocéntrica de causalidad ordinaria, nuestro presente trabajo permite, a diferencia de lo que él piensa, ofrecer una explicación natural a la conexión física entre aquella y procesos causales, como estudiados por la física.

Palabras claves: procesos causales, pseudoprocesos, relatividad especial, cantidades conservadas, ontología.

\title{
Not only causation in the physical world: pseudocausation also matters
}

\begin{abstract}
In this essay we show that some thesis -contended by some authors searching on physical causation- about causal pseudoprocesses, processes of which the most salient aspect seems to be travelling faster than the speed of light, must be rejected o seriously modified. Secondly, we will argue that there is just one non causal entities category and that special relativity does not provide any particular motivation to appeal to an ontological distinction based on identity over time. In addition, this conclusion we will enable us to offer a more accurate definition of a pseudoprocess than that found in the relevant literature. In third place, we will show in some detail how such processes, understood the way that we suggest here, are and have been valuable methodological tools when studying -through usual measurement procedures- effective causal relations holding in the physical world. Finally, we will connect our conclusions with R. Torretti's criticism on the relation between ordinary causation and governed-by-differential-equations physical processes and we will show that, although neutral on his anthropocentric background, the account here argued provides, against what Torretti claims, a natural explanation to the physical connection between ordinary causation and causal processes such as studied by physics.
\end{abstract}

Keywords: causal processes, pseudoprocesses, special relativity, conserved quantities, ontology. 


\section{Introducción}

Una parte de las discusiones filosóficas contemporáneas sobre relatividad especial se ha centrado en el problema, planteado años atrás por H. Reichenbach (Reichenbach 1958 y 1956), de distinguir de una manera adecuada entre un proceso relativista genuinamente causal y uno que no lo es. A este segundo tipo de proceso Reichenbach lo llamó inicialmente secuencia causal irreal, pero preferiremos, siguiendo a W. Salmon (Salmon 1984), llamarlo pseudoproceso (en adelante PSP) o, si se quiere, epiproceso. En una primera aproximación, los PSPs, como indica Reichenbach, parecen definirse adecuadamente como aquellos procesos que parecen justamente violar el límite de la velocidad de la luz c. ${ }^{2}$ Ejemplos típicos de ellos son la traza que generaría un rayo de luz láser enviado desde la tierra y que barre una zona de la superficie de la luna conforme se mueve el puntero láser en la tierra, o el punto de fuga en que se cruzan dos reglas súper lumínicas ${ }^{3}$. Ya que, por esta razón, parecen no trasmitir ninguna información física, no pueden ser considerados secuencias de entidades reales (no parecen interactuar con nada en la dirección de su movimiento) y no pueden ser objeto, por la misma razón, de interés para los físicos practicantes trabajando en teoría de la relatividad especial (en adelante TRE). Sin embargo, en principio parece no haber razones para negar que son procesos y por tanto habitantes de una ontología procesual. ${ }^{4}$ Para Reichenbach, en particular, era fundamental distinguirlos no porque representaran alguna amenaza para la plausibilidad de la TRE sino porque su exclusión era parte de la tarea fundamental de explicar la dirección de la flecha del tiempo sobre bases termodinámicas, mostrando que sólo los procesos causales genuinos pueden manifestar irreversibilidad macro estadística. ${ }^{5}$ De manera que, si se viola el orden temporal, no podríamos tener ya más orden causal.

A partir del trabajo seminal de Reichenbach se ha generado, por consiguiente, una importante discusión acerca de las condiciones de adecuación de cualquier criterio postulado que distinguiese entre PSPs y procesos causales (en adelante PCs) y que, a su vez, sirviese el propósito de caracterizar, en acuerdo con las teorías físicas hoy prevalecientes, el vinculo causal. Esto fue lo que el mismo Reichenbach pretendió al ofrecer su criterio de transmisión de marca como la vía para caracterizar físicamente los PCs genuinos. La subsecuente discusión, liderada fundamentalmente por W. Salmon (Salmon 1984) y P. Dowe (Dowe 2000), ha llevado a abandonar finalmente el criterio original reichenbanchiano y a sustituirlo por otro formulado por Dowe. El criterio de Dowe (o Salmon-Dowe) implica que un proceso (entendido como una línea de mundo en un diagrama de Minkowski) para ser causal, debe poseer alguna cantidad conservada, de acuerdo a como éstas son definidas 
en física. Este entonces es el criterio de posesión de cantidad conservada o CC. ${ }^{6}$ Mucho más importante para nuestra argumentación aquí que evaluar en particular las bondades o las limitaciones de la concepción de CC, será la cuestión acerca del valor per se de los PSPs en la concepción de Dowe. En su opinión, una vez hecha la anterior distinción PC-PSP y asumido el criterio de CC como criterio para caracterizar PCs genuinos, debemos distinguir, a su vez, entre dos tipos de pseudoentidades causales: aquellas que, aun sin poseer $\mathrm{CC}$, presuponen alguna forma de identidad en el tiempo - los PSPs- y aquellas que no la presuponen y que él caracterizará como entidades temporales o espaciales ficticias compuestas (o time/spacewise gerrymanders, en inglés). En segundo lugar, Dowe afirma que las segundas deben ser descartadas como simple "basura física". Finalmente, ya que los PSPs no pueden tampoco jugar ningún rol causal en física y, en particular, en relatividad especial, parece inevitable concluir que, en la concepción de Dowe, la clase completa de las pseudoentidades no puede ser considerada de valor para describir de una manera sustantiva cualquier estado físico en que ocurran genuinas relaciones causales. El propósito de nuestra argumentación en lo que sigue es desafiar y rectificar estas últimas tesis.

\section{Procesos y pseudoprocesos en la teoría causal de Dowe}

Phil Dowe, en la que ha parecido ser la teoría más robusta de causalidad física propuesta hasta ahora en la literatura, afirma que "es la posesión de una cantidad conservada, antes que la capacidad para transmitir una marca, lo que hace a un proceso un proceso causal." (Dowe 2000, p. 89). Así, la teoría de causalidad de Dowe se funda en dos postulados básicos:

1. Un proceso causal es una línea de mundo de un objeto que posee una cantidad conservada.

2. Una interacción causal es una intersección de líneas de mundo que envuelve el intercambio de una cantidad conservada.

Aunque esta teoría obtiene parte de su inspiración teórica de un número importante de filósofos trabajando previamente en causalidad física, entre ellos, Fair, Russell, Reichenbach y el mismo Salmon, ${ }^{7}$ el aspecto diferenciador fundamental de ella, como se ve, es la introducción de la idea de posesión de una cantidad conservada por parte de un objeto, representado por una línea de mundo de carácter físico. Así, para Dowe, los procesos causales no se caracterizan por transmitir marcas desde una región del espacio a otro, sino más bien porque son poseedores de cantidades conservadas físicas como energía, 
momentum, carga eléctrica, etc. Las cantidades dinámicas propias de los teoremas de conservación de la física serán entonces elementos determinantes en el importe causal de los procesos genuinos. Los objetos físicos son procesos causales justamente porque poseen cantidades conservadas. Por ende, en la teoría procesualista de Dowe un objeto se entenderá como "cualquier cosa encontrada en la ontología de la ciencia (tales como partículas, ondas y campos) o en la esfera del sentido común (tales como sillas, edificios, etc.)" (Dowe 2000, p. 91). Para Dowe, según muestra su postulado 2, son los procesos causales genuinos las únicas entidades con capacidad para interactuar. ${ }^{8}$

El postulado 1 establece que un proceso causal es una línea de mundo. Esto indica que los procesos causales evolucionan espacio temporalmente en un espacio tiempo de Minkwoski. Así, una línea de mundo en dicho espacio es una entidad física que se identifica con un proceso causal genuino. Dicho proceso, a su vez, será un objeto con persistencia de cualidades y que exhibirá cantidades conservadas. La evolución de dicha entidad corresponderá, por tanto, a su historia causal completa. La figura siguiente muestra este tipo de líneas de mundo. En él los procesos causales serán representados gráficamente en el dominio del cono de luz (en este caso es un triángulo de luz por tratarse de un espacio tiempo (X,T) bidimensional), donde ocurren las relaciones espacio temporales de tipo tiempo -trazo OA- o tipo luz-trazo OB-. ${ }^{9}$

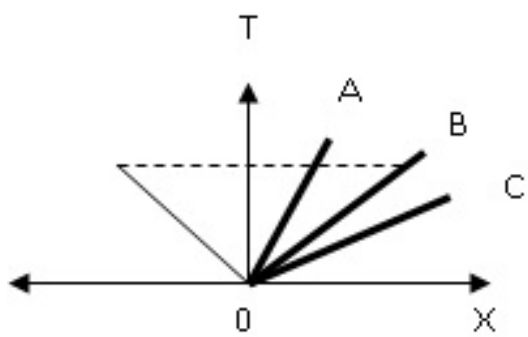

Figura 1. Los intervalos OA, OB y OC son procesos o líneas de mundo. Los intervalos $\mathrm{OA}$ Y OB, están permitidos por la física, y se denominan, respectivamente, tipo tiempo y tipo luz. El intervalo OC no está permitido por la física, ya que los eventos están desconectados físicamente, y se denomina tipo espacio.

Dadas estas definiciones, se pueden ilustrar algunos ejemplos elementales de procesos causales en un diagrama de Minkowski. La figura 2 más abajo representa dos objetos físicos, dos bolas, evolucionando en ese tipo de diagrama. Se puede ver que uno de ellos (la bola A) se mueve horizontalmente hacia la derecha. En este caso, se trata de una línea de mundo cuya relación espacio 
temporal muestra que su rapidez resulta ser mucho menor que la relación espacio temporal de un rayo de luz. Este objeto, aparte de ser un proceso físico de baja velocidad, exhibe posesión de cantidad de movimiento o energía cinética ${ }^{10}$. Por otra parte, la bola $\mathrm{B}$, que permanece detenida, también contará como un proceso causal dado que para Dowe la cantidad conservada nula como el momentum lineal cero de la bola- también integrará la descripción de los procesos físicos pues cuenta como una cantidad conservada.

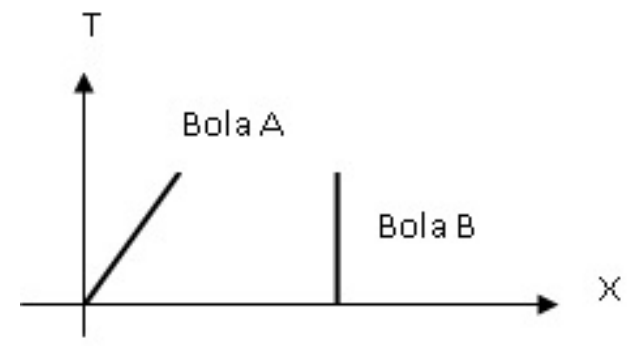

Figura 2. Bolas como procesos causales

En la posición de Dowe, las bolas, que permanecen dentro del cono de luz retratado en la figura 2, cuentan entonces como PCs y, por ello, representan objetos físicos con identidad que evolucionan en el tiempo y respetan el límite $\mathrm{C}$ de rapidez de la luz en el vacío. Por otro lado, de acuerdo a lo ya indicado en el postulado 2 , la relación causal se puede ver como una intersección de estos PCs en el espacio tiempo, lo que significa que sólo ellos pueden conectar dos eventos como relatas auténticos de una relación causal y sólo ellos pueden interactuar y, por ende, transmitir información física. Finalmente, según Dowe, todos aquellos procesos no genuinos que muestren alguna identidad en el tiempo y puedan ser representados en un espacio de Minkowski, calificarán como PSPs, puesto que -al no poseer cantidades conservadas- deberán ser descartados como entidades físicas genuinas.

Ya que, al menos en el contexto de una interpretación dinámica clásica de TRE, todo lo causal es físico y viceversa, el rol que cumplen los PCs en dicha teoría es obvio e indisputable. Sin embargo, esto mismo plantea, a nuestro juicio, una pregunta inevitable acerca de la naturaleza, la definición precisa y el valor de los PSPs o las pseudoentidades al interior de un programa fisicalista de la causalidad tal como el de Dowe. Como mostraremos, la perspectiva de Dowe resulta más bien restringida y generalista acerca de dichas entidades. Así, la definición que provee opera más bien por exclusión tendiendo a generar, por ello mismo, una distinción artificial entre tipos de 
pseudoentidades. Además, permite asumir que, una vez hecha la distinción entre PCs y PSPs, estos últimos no deberían jugar ningún rol sustantivo en la descripción de un estado físico.

Es nuestra convicción, sin embargo, que si nos empeñamos en describir procesual y causalmente el mundo físico, se debe revelar inevitablemente la significancia filosófica, científica y cognitiva de las pseudoentidades -en sus distintas manifestaciones-, ya que, al ser proyectadas en diferentes direcciones espaciales, terminan siendo partes integrantes de nuestros modos de entender y captar el mundo físico y, por añadidura, proveen información relevante de los procesos genuinamente causales que los producen y de los cuales dependen. Es lo que nos proponemos argumentar en las secciones siguientes.

\section{La distinción entre procesos genuinos, pseudoprocesos y time/spacewi- se gerrymanders}

Dowe especifica (en la primera sección del capítulo 5 de su 2000) con gran claridad su ontología física introduciendo una distinción entre gusanos relativistas (worms) que califican como procesos y otros que no califican como tales. En sus palabras:

Worms in spacetime that are not processes I call, ...., 'spatiotemporal junk'. Thus a line on a spacetime diagram represents either a process or a piece of spatiotemporal junk, and a process is either a causal or a pseudo process. In a sense, what counts as an object is unimportant; any old gerrymandered thing qualifies (except timewise gerrymanders). In the case of a causal process, what matters is whether the object possesses the right type of quantity. A shadow, for example, is an object, but it does not possess the right type of conserved quantities; a shadow cannot possess energy or momentum. It has other properties, such as shape, velocity and position, but possesses no conserved quantities. (Dowe, P., 2000, p.91.)

De acuerdo a esta cita, Dowe establece una triple distinción en la ontología relativista: por una parte, genuinas entidades -los procesos causales genuinos o PCs- , y por otra, no-entidades, entre las que caen los PSPs -que siguen siendo procesos- y los timewise gerrymanders (de aquí en adelante TWG), que resultan ser basura espacio temporal. Del texto se sigue también que sólo los primeros poseen "el tipo correcto de cantidad conservada". En cambio, de los segundos -los PSPs- podemos decir que, aunque posean ciertas propiedades -forma o velocidad-, no poseen aquellas cantidades. El ejemplo favorito de estos, para Dowe, son las sombras. Los terceros son -como se ve- sim- 
plemente descartados. Así, si aceptamos esta distinción, tendríamos que reconocer sólo a las sombras, los puntos individuales de luz láser superando $\mathrm{c}$ o los puntos de fuga en el cruce de las reglas superlumínicas imaginados por Reichenbach como PSPs. Hasta este punto no tenemos todavía ejemplos de $T W G s$ en la mencionada ontología, ni una explicación precisa de en qué difieren de los PSPs en tanto no-entidades físicas. Dicha explicación sobreviene en la tercera sección del citado capítulo. Allí Dowe afirma acerca de su teoría:

According to the CQ theory, there are causal processes such as billiard balls rolling across tables, and pseudo processes such as shadows and spots of light. Is this exhaustive of all items that may be represented as occupying a spacetime region? The answer is no; there is also"spatiotemporal junk" - items that are not processes at all on the CQ definition. An example is what I earlier called "timewise gerrymanders." A timewise gerrymander is a putative object defined over a time interval where the definition changes over time (the putative object is really different objects at different times). (Dowe 2000, p. 99)

Esta cita sugiere lo que parece ser la clave, según Dowe, para distinguir los dos tipos de no-entidades: los $T W G s$ no manifiestan ninguna identidad a través del tiempo pues en el fondo son "diferentes objetos en diferentes tiempos". De esto se infiere que, en contraste, los PSPs sí presuponen una forma de identidad en su propia evolución, lo que puede parecer claro al analizar las sombras pues ellas son manifestaciones de objetos -que son PCs a su vez, los cuales permanecen idénticos en diferentes tiempos. ${ }^{11}$ Así, el contraste descansa en una distinción metafísica entre identidad vs. falta de identidad. Apelando a este contraste, a continuación Dowe busca disolver una crítica de Salmon a la primera formulación de su teoría. La enunciación de Dowe del contraejemplo de Salmon es la siguiente:

In his criticism of the Conserved Quantity theory just presented, Salmon ... offers an argument (see ... 1984:145-146) for requiring 'transmits' rather than just 'possesses': Consider a rotating spotlight spot moving around the wall of a large building. This is a classic case of a pseudo process: in theory such a spot could move faster than the speed of light. But the spot manifests energy at each point along its trayectory. Therefore, Salmon's argument goes, we need more than just the regular appearance of energy to characterise causal prossees; we need the notion of transmission. (Dowe 2000, p. 98)

El punto fundamental de Salmon es que cuando consideramos una traza completa de los puntos de luz del láser rebotando en la pared tenemos efectivamente -lo que es corroborado cotidianamente por la percepción- un 
objeto que despliega continuidad espacio temporal, cierta persistencia y que en cada punto que lo constituye posee efectivamente cantidades físicas. Pero sabemos, además, que, dado cierto límite, dicha traza puede violar $\mathrm{C}$ en la dirección del movimiento. Esto desde luego representa un contraejemplo a la teoría de Dowe, pues podría satisfacer los postulados indicados anteriormente y contar como un PC. La respuesta de Dowe es considerar la traza completa del láser como un $T W G \mathrm{y}$, por ende, descartarlo como proceso. He aquí la replica de Dowe:

So, turning to Salmon's example of the aggregate of the patches of wall sequentially illuminated, we can see that although it is generated by a single description, involves some uniformity, and displays spatiotemporal continuity, it nevertheless is a timewise gerrymander, and not in fact an object on my definition, since it does not display identity over time. The spot itself is on object (although not causal), and the entire patch of wall is an object (like the ten billiard balls), but the timewise gerrymander is not. It therefore is not a process of any sort, let alone a causal process; it qualifies on my account as spatiotemporal junk. (Dowe 2000, p. 101)

Es interesante observar cómo el final de la respuesta introduce una sutil ambigüedad en el planteamiento de Dowe entre su primera interpretación de los puntos de luz móviles y la que introduce ahora. De acuerdo a lo que se indica, tenemos aquí dos situaciones que deben ser distinguidas, por un lado, cada punto singular que rebota o interactúa en cada parte de la pared y cuya sumatoria exhibirá un objeto constituido de distintos objetos en distintos tiempos, dando origen, en ese caso, a un TWG desprovisto de identidad, y, por otro, la secuencia de los puntos de luz, que al golpear en cada parte de la pared, aparentan el movimiento de un punto lumínico idéntico a lo largo de la pared, dando origen, en ese caso, a un PSP que, consecuentemente, gozará de identidad. Por tanto, bajo ambas interpretaciones, efectivamente el mismo fenómeno puede contar como un $T W G$ o como un PSP. Más allá de una cuestión de indefinición ontológica, tal vez menor, el problema es que los primeros efectivamente califican como basura física para Dowe y no tenemos claro por qué ese dictamen no se debería aplicar a los PSPs también. Desde luego, si es posible defender la distinción entre ambas no-entidades sobre una base física y metafísica plausible, cada una debería recibir un tratamiento diferente. Si no hay razones físicas ni metafísicas que motiven de una manera sustantiva la mencionada diferencia entonces la opción inevitable es la unificación ontológica. Más importante aún, mientras esa cuestión no se resuelva, tampoco es posible formular una definición unívoca de lo que sea un PSP y 
la misma teoría de la causalidad basada en CCs permanecerá, por tanto, ontológicamente indefinida. Con el propósito de examinar esta cuestión e intentar resolverla, debemos clarificar cómo, desde nuestra perspectiva, podemos modelar TWGs en física.

\section{Modelando TWGs en física relativista}

Dowe ofrece el siguiente ejemplo ilustrativo de un TWG,

An example of a timewise gerrymander is the putative object $\mathrm{x}$ defined as:

for $t i<t<t 2 ; x$ is the coin in my pocket

for $t 2<t<t 3 ; x$ is the red pen on my desk

for $t 3<t<t 4 ; x$ is my watch.

Notice that $x$ occupies a determinate spacetime region, and that at any time in the interval $t i$ to $t 4, x$ 'possesses' conserved quantities such as momentum (although not strictly speaking, for something must be an object in order to possess a conserved quantity). Clearly, there are innumerable such timewise gerrymanders. (Dowe 2000, p. 99)

En la descripción de este primer ejemplo, los elementos constituyentes del objeto X ocupan distintas posiciones espaciales en los diferentes tiempos mencionados. Este tipo de TWG difícilmente podría ser tomado en serio como un proceso y menos aun como proceso causal, puesto que intuitivamente no acostumbramos a percibir ni pensar algún objeto que permanezca, en el tiempo, desmembrado en distintos lugares espaciales, y siendo cada una de ellas totalmente diferentes entre sí. Difícilmente se podrá imaginar la sucesión de una moneda, un lápiz y un reloj, en distintos lugares, como un mismo objeto desde t1 hasta 4 -aún cuando los distintos lugares estén ubicados en una sola dimensión espacial-, a menos que alguna persona esté habituada a creer que una moneda, un lápiz y un reloj puedan tener algún tipo de causa común. Una forma de representar esto es la siguiente: 


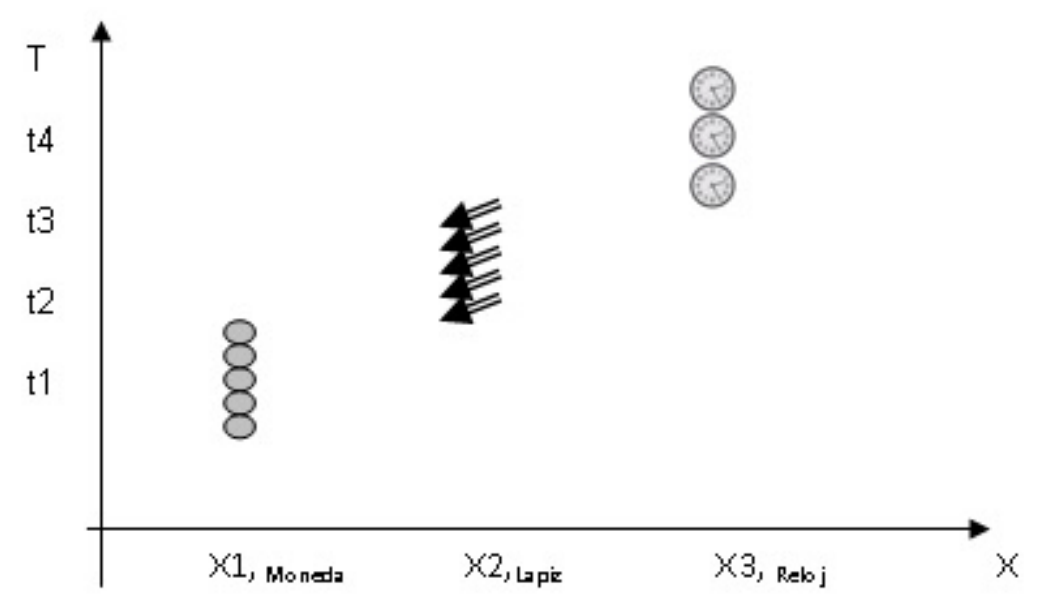

Figura 3. TWG compuesto de tres objetos distintos: Moneda, lápiz y reloj.

Un aspecto característico del anterior ejemplo de TWG era su ausencia obvia de genidentidad ontológica y de similaridad estructural, tal como imaginaba Dowe. Sin embargo, es posible representar grados crecientes de similaridad observacional para TWG utilizando los mismos medios de representación de procesos físicos genuinos en TRE. Así podemos imaginar tres situaciones distintas. Un primer caso podría consistir en imaginar 6 monedas repartidas en dos clases distintas de tres miembros cada una. Tres monedas de 50 pesos chilenos y tres monedas de 100 pesos chilenos. Si las ubicamos en una línea recta, intercaladas en el eje X, entonces al fijar la atención sobre cada una de ellas sucesivamente en el mismo intervalo de tiempo se obtiene la siguiente representación. 


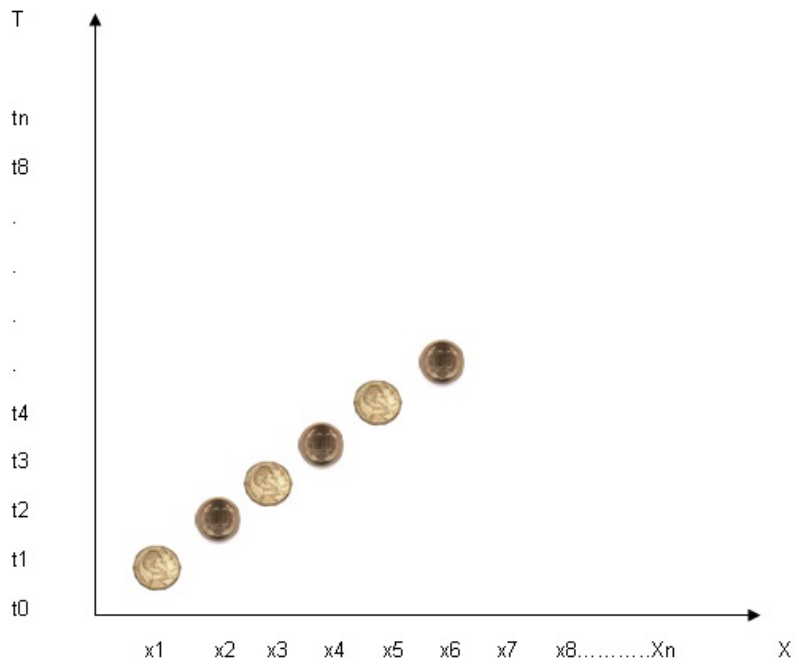

Figura 4. TWG compuesto de seis objetos en dos clases de monedas diferentes.

Queda claro, de acuerdo a la imagen, que la similaridad de estructura ahora es mayor que la anterior. Es decir, hay un mayor grado de identidad. Podemos obviamente incrementar adicionalmente la similaridad manteniendo la misma distribución espacial anterior y sustituyendo las monedas de cien pesos por monedas de cincuenta pesos. Este podría ser un segundo caso posible de representar de la manera que indica la figura 5.

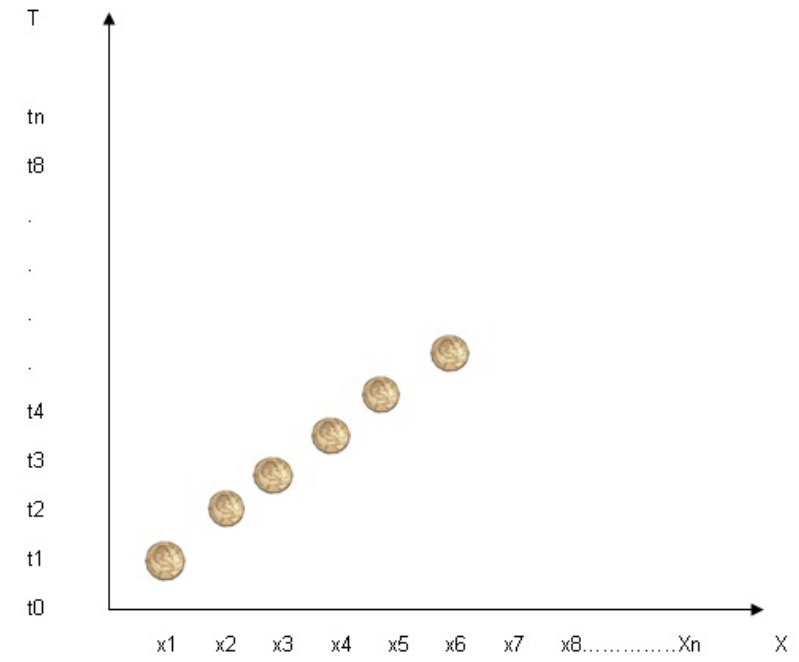

Figura 5. TWG compuesto de seis monedas de similar estructura. 
Naturalmente que las monedas en la figura 5, aunque sean distintas, representan un todo mereológico con similaridad estructural en el espacio de Minkowski. Aunque es claro que las monedas podrían ser marcadas para diferenciarlas, es claro también que observacionalmente su secuencia conjuntiva perfectamente puede representar una entidad de naturaleza procesual, al igual que un PSP de puntos de luz que se despliega en la pared debido al movimiento de un punto de luz láser (pudiendo ser incluso continua). Es decir, si cambiásemos las monedas por puntos de luz en la pared obtendríamos la misma similaridad de estructura, así como la obtenemos utilizando monedas como en el diagrama anterior. La siguiente figura muestra este tipo de objeto con puntos de luz.

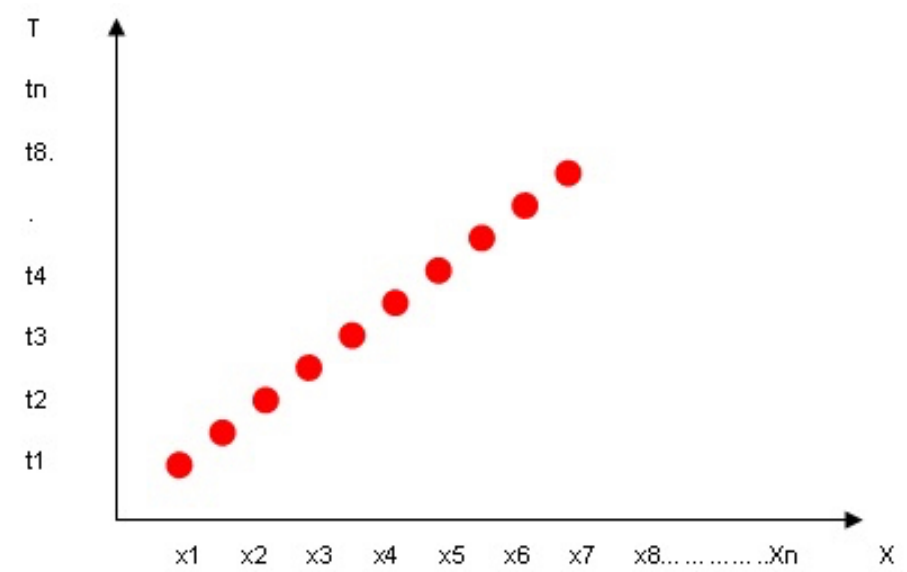

Figura 6. TWG o PSP compuesto de puntos de luz que recorren la pared como proceso.

De acuerdo a lo afirmado anteriormente, es claro que la TRE permite representar ambos, tanto el haz de luz como la secuencia de monedas, como tipos de procesos. Por otro lado, sabemos que no hay nada en dicha teoría que permita hacer una diferencia esencial entre la identidad de un punto de luz y la identidad de una moneda, en la medida que ambas entidades exhiben cantidades conservadas.

Del examen de estas representaciones de TWGs se sigue, a nuestro juicio, que sus semejanzas con los PSPs son naturales. Se pueden señalar al menos estas tres: 
a. Pueden o no rebasar $\mathrm{C}$.

b. Considerados -aunque sea inapropiadamente- como objetos singulares no poseen CCs, aunque cada una de sus partes espaciotemporales las puedan poseer.

c. Pueden manifestar continuidad y ambos pueden representar cosmolíneas minkowskianas.

Desde luego, la única diferencia que subsiste, de acuerdo a lo que sostiene Dowe, es metafísica: los TWGs no despliegan identidad a través del tiempo y los PSPs, en cambio, la deben presuponer ${ }^{12}$.

Nuestra interpretación sobre la insistencia de Dowe en apuntar a la identidad como el criterio distinguidor de lo que cuenta como un PSP es que ella está basada en una tesis de fondo que la física, en particular la física relativista, no requiere como un criterio de adecuación pero que la visión metafísica de Dowe parece implicar: la idea que la identidad es una noción primitiva y que la causalidad y, con ello, los PCs, dependen de ella ${ }^{13}$. Ya que hemos argumentado en extenso en otro lugar contra esta postura, ${ }^{14}$ lo que podemos decir aquí es que esta tesis de primitivismo de la identidad es debatible por dos razones. En primer lugar, parece incongruente con una concepción de la causalidad inspirada en una filosofía humeana, como resulta serlo la misma concepción de Dowe ${ }^{15}$. Como sabemos, Hume apoya una concepción causal de la identidad y Dowe está defendiendo en este punto lo contrario. ${ }^{16}$ En segundo lugar, por lo que hemos visto más arriba, la física relativista (y presumiblemente la física cuántica) parece no requerir una tesis fuerte de genidentidad física. La identidad en dicha física, en cambio, puede venir en grados $\mathrm{y}$, en vez de hablar de objetos que evolucionan establemente en el tiempo, parece suficiente hablar de todos mereológicos que ganan o pierden identidad, dados sus cambios de estado. Así, los PSPs y los TWGs tienen grados inferiores de identidad, aunque levemente diferentes entre sí, y supervienen en procesos físicos genuinos que exhiben grados superiores, tal vez máximos, de identidad. ${ }^{17}$

Por lo anterior nos parece natural concluir que cualquier concepción de causalidad física de base procesual no requiere distinguir entre PSPs y TWGs. Estas entidades participan de una misma categoría, la categoría de las pseudoentidades causales con contenido físico. Adicionalmente, podemos agregar otras cualidades que las hacen participar de la misma categoría. Primero, ambas siempre se relacionan -mediante una relación de superveniencia u otra semejante- con entidades causales o procesos causales. ${ }^{18}$ Segundo, ambos tie- 
nen realidad perceptual u observacional. Tercero, tanto en física clásica como no-clásica y, tal vez, en otras áreas del discurso científico, los PSPs y los TWG son igualmente útiles y valiosos para resolver problemas de medición en el mundo de los procesos físicos genuinos. Esta, en nuestra opinión, es la razón decisiva para rechazar el dictamen de Dowe según el cual los TWG representan basura física y para, por extensión, desconsiderar a los PSPs como instrumentos de alguna utilidad en la descripción de cualquier estado físico. Además, es una razón crítica para unificar ambos tipos de entidades en una misma categoría. Ambos son, en realidad, parte de una misma dimensión de pseudocausalidad y ambos pueden ser igualmente útiles. Mostraremos este punto con cierto detalle en las próximas secciones. Antes de hacer eso, debemos precisar las definiciones que estaremos usando hasta el final del artículo.

A partir de lo mostrado en esta sección, estamos en condiciones de extraer la siguiente definición de la categoría ampliada de los PSPs:

Un proceso es un PSP si y sólo si es un epi-objeto o agregado mereológico superveniente en procesos físicos que a) puede o no violar la constante $C$ de la rapidez de la luz, b) no posee cantidades fisicas conservadas en la dirección del movimiento, c) puede exhibir cierta continuidad estructural a través de cambios de estado y d) que, si viola $C$, implica reversión temporal.

Se debe notar que esta definición no hace descansar la pseudocausalidad ni en una simple desconexión física factual en algún punto del espacio tiempo, ni en la restricción relativista de no transmisión de información entre señales. Lo primero pues no estamos suponiendo que la simple separación espacial de dos eventos en un mismo tiempo $t$ permita obtener PSPs por fiat pues ello descartaría que estos evolucionan como todos mereológicos exhibiendo continuidad estructural (la que implica propiedades físicas). Lo segundo pues, aunque ellos -desde la perspectiva de la dirección del movimiento- efectivamente no portan ni transmiten información física o de otro tipo, sí lo hacen de un punto del espacio tiempo a otro a través de la dirección determinada por los procesos causales genuinos que los engendran. Examinaremos esto con más detalle en la próxima sección. ${ }^{19}$ 


\section{PSPs, medición y experimentación}

Aclarada la definición de un PSP que nosotros favorecemos y la unificación ontológica que ella supone, es fundamental mostrar ahora que ella permite mostrar y entender la vasta utilidad metodológica que los PSPs cumplen tanto en física prerrelativista como relativista e incluso más allá de la misma física. En nuestra opinión, mostrar esto es la mejor forma de sugerir que las tesis de Dowe sobre la naturaleza ontológica de los PSPs y su eventual valor en física son a lo menos confundentes e imprecisas. A ello nos abocaremos en esta sección.

\section{a. Historia de la física e ilusiones}

Una forma natural de admitir que somos víctimas constantemente de ilusiones físicas proviene de experiencias con sombras. Todos parecemos reconocer que, aunque ellas se basan en entidades físicas, la información que nos pueden entregar de estas últimas no es confiable. Sin embargo, reconocemos también que nos sentimos autorizados a hablar de ellas como si tuvieran alguna forma de existencia en el espacio tiempo. En esto justamente consiste su poder ilusorio. Con razón entonces las podemos llamar, de manera general por el momento, pseudoentidades físicas. Sin embargo, el reino de las pseudoentidades va mucho más allá del reino de las sombras. Piénsese, por ejemplo, en la señal luminosa proyectada perimetralmente por un faro y observada por un marino desde la distancia una noche neblinosa. Es obvio que, en este caso, diríamos, contra lo que pensaríamos normalmente de las sombras, que la ilusión creada en el marino es algo en lo cual él debería confiar ciegamente. Sin embargo, los ejemplos de pseudoentidades cotidianas no se limitan en lo absoluto a casos en los que la luz, o la ausencia de ella, juegue un papel privilegiado. Descubrimos muchos de ellos sobre todo cuando atendemos a fenómenos que se despliegan en el tiempo articulando una forma de proceso, aunque manteniendo cierta persistencia. Piénsese por ejemplo en el llamado efecto de la "ola", al que una muchedumbre en un estadio puede dar origen decidiendo espontáneamente ponerse de pie de manera secuenciada y sincronizada. Lo que parecemos observar entonces es un movimiento desplegándose en una determinada dirección y que parece obedecer a una cierta dinámica. Finalmente encontramos procesos físicos ilusorios de base mecánica. Seguramente podríamos encontrar un buen análogo del ejemplo de la luz láser en el uso de un potente chorro de agua o pintura proyectado rápidamente en una pared. $\mathrm{O}$ en el barrido del disparo de una ametralladora a la misma velocidad. Todo lo que se obtenga en la pared es el resultado de un proceso 
cuya continuidad e identidad es, aunque a veces no lo creamos en el caso del agua o la pintura, ilusoria en la dirección que el agua, la pintura, o las balas se mueven en la pared. De acuerdo a la definición acuñada en la sección previa, ellos deben calificar entonces como PSPs físicos.

En una primera aproximación, podríamos decir que, ya que los PSPs involucran genuinas ilusiones físicas, es del todo esperable que las ciencias físicas no muestren interés alguno por ellos. Sin embargo, declarar esto ciertamente sería incurrir en un serio error histórico. Desde las aplicaciones más tempranas de la física se sabe que ella ha apelado a pseudoentidades, en particular, sombras, para determinar diversas mediciones del entorno físico. Por ejemplo, Aristarco de Samos en siglo III, A-C., utilizando luz y sombra, estimó la razón entre los tamaños de la Tierra, la Luna y el Sol y entre las distancias entre nuestro planeta y dichos astros. Aunque sus estimaciones no fueron suficientemente exactas, estaba empleando un método que al alcanzar mayor precisión resultaría muy eficiente. Torretti describe este experimento de Aristarco de la siguiente manera:

Cuando la Luna L, vista desde la Tierra T, aparece dividida en dos mitades, una oscura y la otra iluminada por el Sol S, las rectas LT y LS forman un ángulo recto. Un observador colocado sobre la Tierra puede medir el ángulo $\alpha$ entre la recta TL en dirección de la Luna y la recta TS en dirección del Sol (Torretti,R., 2007a, p. 98 ).

La siguiente figura ilustra a su vez esta descripción.

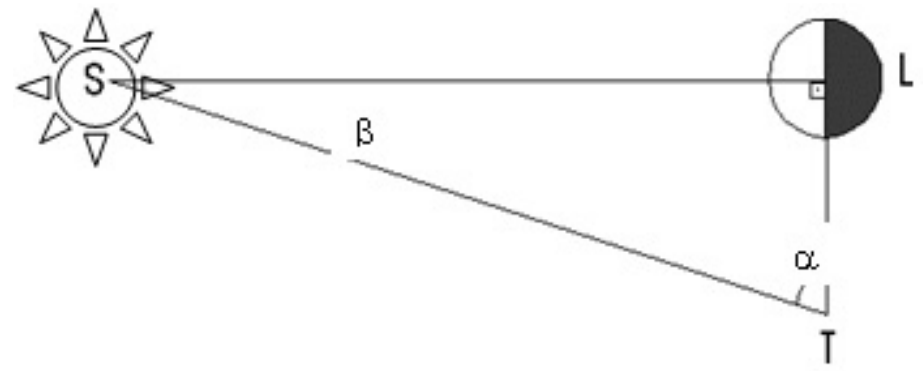

Figura 7. Posiciones relativas entre la Tierra, el Sol y La Luna.

Es decir, a partir de la medida del ángulo $\alpha$ se puede establecer la relación entre la distancia que hay entre la Tierra y la Luna y la Tierra y el Sol. Aristarco estimó que la distancia al Sol es del orden de 19 veces la distancia a la Luna. 
Como este, encontramos muchos otros ejemplos históricos en los que los físicos han apelado a proyecciones geométricas de sombras y haces lumínicos para determinar longitudes asociadas a cuerpos o volúmenes. Esto muestra obviamente que las sombras han sido desde la antigüedad una herramienta fundamental para llevar a cabo mediciones empíricas con valiosas aplicaciones prácticas (para un examen de alguno de estos ejemplos Cf. Quezada y Pavez, 2011).

\section{b. PSPs en física experimental pre-relativista}

Más allá de los testimonios históricos referidos en la sección anterior, se puede mostrar que los PSPs están vinculados con la física experimental newtoniana, en particular, con la mecánica y la dinámica, en la medida que muchas mediciones en aquellas áreas presuponen procedimientos pseudoprocesuales. Estos, nosotros creemos, son hechos tácitamente reconocidos en la práctica de la física experimental newtoniana aunque inadecuadamente explicitados desde la perspectiva metodológica. Desde luego, es fundamental clarificar aquí que no estamos afirmando que tales mediciones ( $u$ otras en otras áreas de la física) basadas, de acuerdo a los que mostramos, en PSPs no se podrían hacer apelando a otros recursos directos. Esto es obvio para nosotros y nuestra argumentación presupone que los procedimientos indicados aquí pueden ser tan alternativos como cualquiera otro en experimentación. Lo único que buscamos relevar es el valor que tiene y siempre ha tenido obtener información física sustantiva a partir de pseudoentidades físicas.

Aclarado esto, procedemos a continuación a ilustrar una situación experimental de naturaleza mecánico-óptica que involucra un PSP.

\section{b.1. Un PSP óptico que mide un proceso mecánico}

Un procedimiento de medición interesante que supone la apelación a PSPs, es aquel que se usa en física escolar para inferir la velocidad angular de nuestro planeta en relación a su eje. Este procedimiento consiste en hacer pasar un flujo de luz a través de un agujero hecho en la cubierta de un material opaco, que, por ejemplo, puede ser la cubierta de una mesa plástica con un orificio pequeño en su centro. A continuación se dispone que la luz solar atraviese el orificio de manera que alcance el suelo, sobre cuya superficie hemos fijado un papel blanco. Si dejamos transcurrir un lapso de tiempo razonable, el punto de luz se desplazará de manera aparentemente continua en la superficie del papel, generando una lenta pero clara trayectoria. Por ejemplo, 
si el lapso de tiempo toma 10 minutos aproximadamente, se podrá observar un lento desplazamiento del punto luminoso del orden de unos $4 \mathrm{~cm}$. Este fenómeno de movimiento permite evidenciar que el sol se mueve respecto a la superficie de la tierra, o, de manera inversa, que la tierra gira sobre su eje respecto al sol, que se supone fijo. La siguiente figura muestra el montaje experimental en el centro y tanto a la izquierda como a la derecha el punto de luz desplazado los $4 \mathrm{~cm}$.
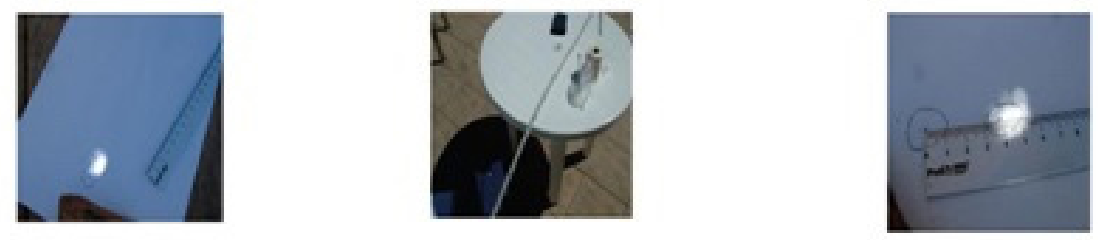

Figura 8. La imagen de la izquierda muestra el punto de luz en el inicio del proceso y el de la derecha el punto final. En el centro se puede ver el montaje experimental.

En estas condiciones, bastará entonces con utilizar el tiempo medido, el desplazamiento del punto de luz en el papel (h) y la distancia desde el agujero hasta la base del suelo (d) (si se quiere obtener la distancia D, que corresponde a $1 \mathrm{U}-\mathrm{A}$ ), para inferir a través de una simple relación geométrica, que se ilustra en la figura siguiente, la velocidad angular de nuestro planeta $(\mathrm{w}=$ $\mathrm{V} / \mathrm{D}=\mathrm{h} / \mathrm{td}$ ), cuyo valor es del orden de $7 \times 10^{-5} \mathrm{rad} / \mathrm{s}$ (si se quiere calcular $\mathrm{V}$ se debe utilizar la distancia $\mathrm{D}$, cuyo valor corresponde a $1 \mathrm{U}-\mathrm{A}$ o $1.49 \times 1011 \mathrm{~m}$ ).

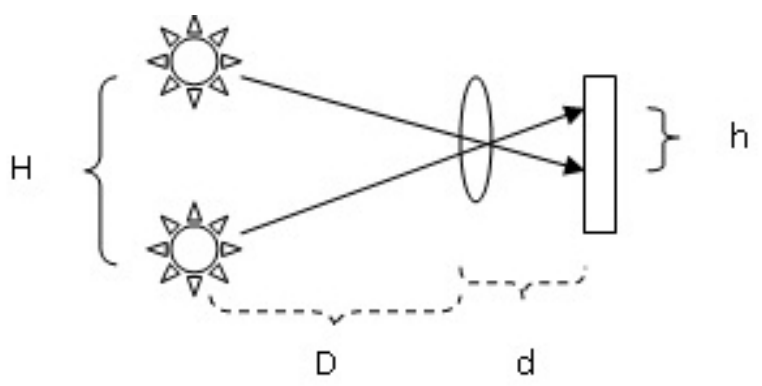

Figura 9. Esquema de representación para el proceso medido.

Es decir, se ha medido una magnitud mecánica (cinemática) a través de un PSP lumínico o electromagnético. ${ }^{20}$ 


\section{c. PSPs y su utilidad en procesos de medición en TRE}

Como hemos indicado en la subsección anterior, la apelación a PSPs en la práctica de la física experimental newtoniana o pre-relativista es un rasgo metodológicamente valioso, en la medida que muchos de sus procedimientos de medición parecen presuponerlos. Sin embargo, en el terreno de la física contemporánea, en particular, en el ámbito de la TRE, el asunto puede ser muy diferente. Ya que la distinción entre PCs y PSPs surge en el contexto de dicha teoría, es natural-como sostiene Dowe- imaginar que los últimos no jueguen ningún papel relevante en ella. Nosotros creemos que es posible mostrar que dicha sugerencia no puede ser tomada seriamente si somos honestos con lo que se hace en TRE. Para ilustrar este punto, nos concentraremos en procesos de altas energías, en particular, procesos que implican chorros de partículas de núcleos galácticos activos (AGN). Es evidente que no podemos interactuar directamente con este tipo de proceso por dos simples razones: en primer lugar, porque se encuentran muy distantes de nuestro planeta y, en segundo lugar, porque, aunque pudiésemos acercarnos lo suficiente, los altos niveles de energía que poseen impedirían físicamente nuestro trabajo. Sin embargo, la cosmología contemporánea ha encontrado maneras indirectas de capturar la información física relevante que proviene de dichos centros galácticos, focalizándose en la radiación electromagnética que emiten al espacio en todas las direcciones, como consecuencia de los procesos físicos que ocurren en su interior. Mostraremos en lo siguiente que los más interesantes procedimientos de medición indirecta de dicha radiación se llevan a cabo apelando a alguna forma de PSPs electromagnéticos, ya sea a velocidades cuyos módulos sean menores que la rapidez de la luz o mayores que ella, y que es esto lo que los hace procesos susceptibles de ser estudiados apelando a RE.

Un ejemplo dramático de dicha medición pseudoprocesual en procesos cosmológicos de altas velocidades que se generan en AGN son aquellos que presuponen la supuesta presencia de agujeros negros súper masivos en su interior. Un ejemplo de este tipo reportado recientemente, corresponde a la radiogalaxia tipificada con la serie $3 \mathrm{C} 120$. Dicha galaxia tiene la particularidad de enviar un chorro de materia lumínica radiante con un ángulo pequeño, respecto a la línea de visión terrestre, y con una gran velocidad - muy cercana a C-, generando con ello un PSP electromagnético súper lumínico en la zona del laboratorio terrestre. ${ }^{21}$ 

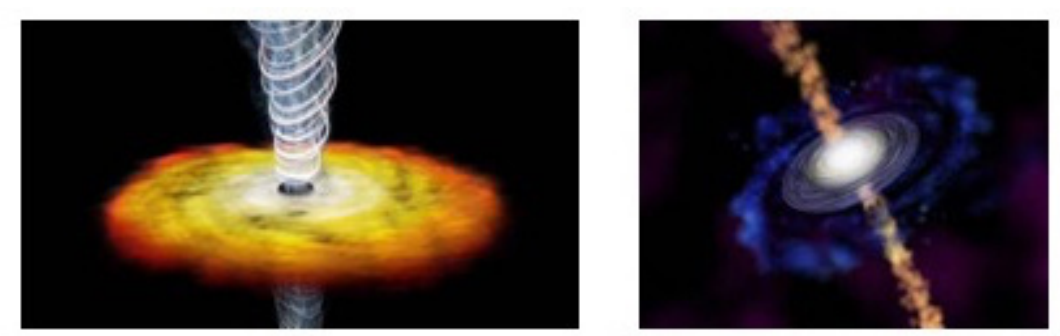

Figura 10. Dos perspectivas de un centro galáctico activo.

En este sistema, de genuinos PCs y PSPs, deben considerarse tres tipos de procesos: el primero corresponde al chorro o componente, que es un auténtico PC que se desplaza a una rapidez de $0.9 \mathrm{C}$; el segundo consiste en la información electromagnética o radiación que se desplaza en el vacío con rapidez $\mathrm{C}=3 \times 10^{8} \mathrm{~m} / \mathrm{s}$, que también es un PC y es el conjunto de procesos que arriban a nuestro planeta; y el tercero es el PSP compuesto de las distintas interacciones entre la información electromagnética o radiación y el instrumento de captación en nuestro planeta.

A continuación exponemos visualmente el esquema del chorro y la forma en que se detecta, desde nuestro planeta, la radiación enviada por este, y que permitirá formar en los detectores terrestres el PSP medido. La imagen ilustra, además, el vector velocidad del chorro (flecha blanca diagonal), que alcanza una velocidad cuya magnitud es casi tan grande como la rapidez de la luz en el vacío (0.9C). Con color blanco, pero en flecha dirigida hacia abajo, se observa el vector que representa a la velocidad de la luz en dirección hacia nosotros. Para el chorro de la radio galaxia 3C120 la angulación del chorro respecto a la dirección en que viaja la luz hasta nuestro planeta corresponde aproximadamente a $20^{\circ}$. 


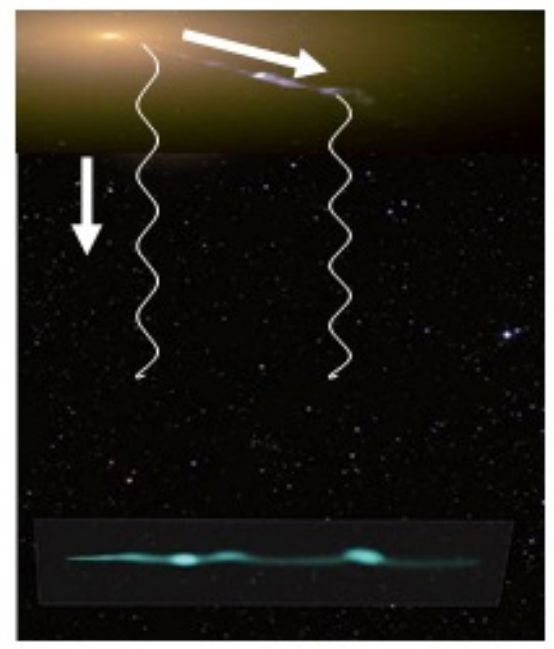

Figura 11. Esquema que muestra el chorro galáctico relativista y dos señales de luz en dirección a nuestro planeta.

A continuación exponemos el esquema de medición de los procesos involucrados. Según se aprecia en la imagen anterior, los tres tipos de procesos ocurren en el plano X-Y. El desplazamiento del chorro tendrá entonces una componente en el eje $\mathrm{Y}$, dada por $\mathrm{V} \Delta \mathrm{t} \cos \theta$ y otra en el eje $\mathrm{X}$, dada por $\mathrm{V} \Delta \mathrm{t}$ $\operatorname{sen} \theta$. Luego, habrá tres velocidades a relacionar: la velocidad del chorro, $\mathrm{V}$, la velocidad de la radiación, C, y la velocidad del PSP, que identificaremos con el símbolo $\mathrm{V}_{\text {PSP. }}$

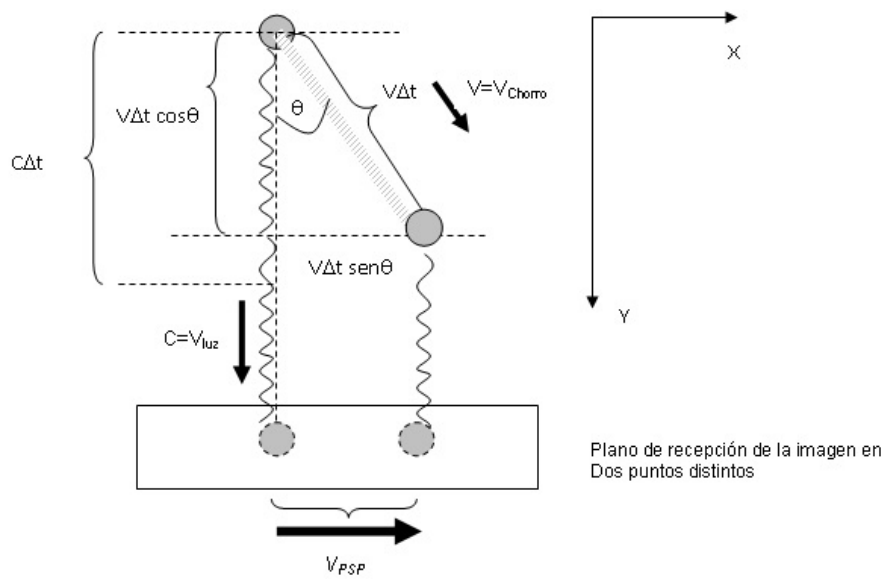

Figura 12. Representación geométrica del chorro galáctico relativista, las dos señales de luz dirigidas hacia nuestro planeta y el PSP medido en los instrumentos terrestres. 
Aplicando algunos teoremas básicos a los elementos geométricos del esquema esbozado y considerando los principios de la RE, se puede derivar fácilmente una relación entre los módulos de la velocidad del chorro ${ }^{22}, \mathrm{~V}$, de la velocidad de la luz, C, y de la velocidad del PSP que se genera en el plano de recepción, $\mathrm{V}_{\mathrm{PSP}}$. La mencionada relación es la siguiente:

$$
V_{P S P}=\frac{V \operatorname{sen} \theta}{1-\frac{V}{C} \cos \theta}
$$

Si tomamos un ángulo de $20^{\circ}$ y una velocidad $\mathrm{V}=0.9 \mathrm{C}$, para el caso del chorro cosmológico que hemos descrito, entonces la velocidad del PSP capturado en nuestro planeta resultará de magnitud, $V_{P S P}=2 C \cdot .^{23}$ Es decir, se revela un PSP súper lumínico.

De acuerdo a lo que hemos venido mostrando en este trabajo, nada de esto es metodológica ni epistemológicamente problemático, pues, como ya mostramos, los PSPs se pueden mover a cualquier velocidad, sin importar su naturaleza, y pueden ser medidos de diferentes maneras dependiendo de la teoría del caso.

\section{Más allá de la física de la medición}

En esta sección sugeriremos cómo podemos detectar la presencia de PSPs, bajo nuestra definición, en áreas relacionadas con procesos perceptuales o de otro tipo que no parecen tan estrechamente conectados con conocimiento físico. Como es obvio, dado que asumimos aquí que todo PSP debe supervenir en un PC, es inevitable admitir que si es posible ampliar la esfera de la pseudocausalidad, en algún sentido se amplía también el alcance de la misma causalidad. Pensamos además que, incluso si las definiciones de procesos e interacciones físicas genuinas sufriesen serias modificaciones (por ejemplo, abandonando una definición basada en CCs), el hecho de constatar la difundida y penetrante presencia de los PSPs tanto en física como más allá de ella, exigiría recuperar la superveniencia -o alguna relación semejante- de estos en alguna forma de causalidad que, incluso, pueda suponer componentes no físicos. ${ }^{24}$ Con ese propósito, proponemos aquí dos ejemplos cuyos constituyentes relevantes son tanto físicos como no-físicos y que, al ser modelados de manera simple, revelan aspectos interesantes sobre la conexión entre lo causal y lo pseudocausal. Además, el primero representa un PSP de tipo SWG y el segundo de tipo TWG. 
a. Imágenes ópticas tridimensionales

Según la teoría óptica clásica una imagen es real si se puede proyectar en una pantalla, si no es así entonces es virtual. En términos observacionales se dice que una imagen real se forma fuera del sistema óptico, en cambio, una imagen virtual lo hace dentro del sistema óptico. Por ende, una imagen tridimensional califica como una imagen real, en este sentido. Lo interesante es que al intentar modelar cómo ella se genera obtenemos un esquema más complejo de dos PSPs relacionados con un PC a la base. Así, el origen de la imagen puede ser un objeto cotidiano de talla media que califica entonces como un PC y que genera, a su vez, la colección de todos sus puntos ópticos coexistiendo simultáneamente en el espacio o lugar de origen de la imagen. Este es entonces un PSP óptico que superviene en el PC. A partir de ahí, la señal óptica se proyecta a todas las partes del espacio, generando finalmente otro PSP en nuestra retina, esto es, una imagen tridimensional estrictamente similar o análoga a la que tenemos del objeto que subyace bajo el aparato y que es claramente sensible al tacto. Así, este PSP debe supervenir al primero
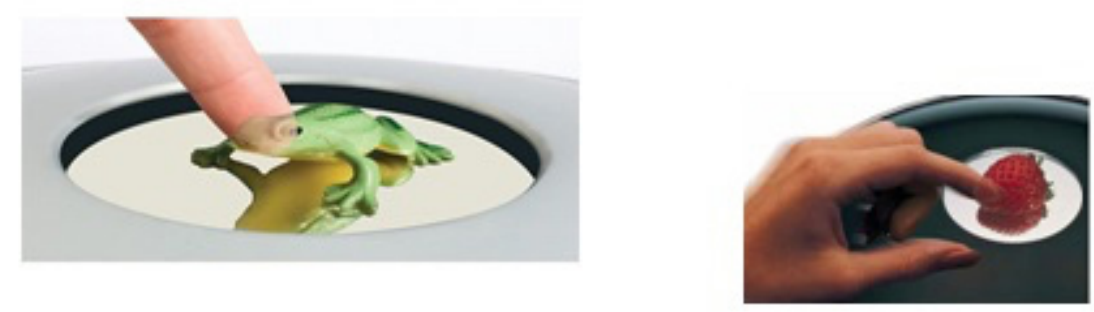

Figura 13. A la izquierda una rana proyectada como imagen óptica real 3D y a la derecha una frutilla.

A continuación, proponemos una forma muy simple de explicar en óptica cómo se forma una imagen tridimensional real. El sistema óptico constará en este caso de dos espejos cóncavos y un objeto ubicado estratégicamente en el foco del espejo superior, el cual se verá reflejado en ellos. El siguiente esquema muestra la distribución de cuatro rayos de luz que son lo mínimo necesario para construir geométricamente la imagen (en este caso el objeto tiene la forma de una casita). Como el objeto está constituido de una multiplicidad de puntos, cada uno de ellos refleja hacia el espejo un rayo, generando entonces infinitos rayos de luz. Desde luego, cada uno de estos rayos cumple la ley de reflexión al llegar al espejo superior o inferior. Además, con dos rayos podemos formar la imagen de cada punto del objeto. Por ejemplo, podemos formar un primer punto con rayos que representamos por medio de 
líneas continuas y un segundo punto de la imagen con dos rayos más, que representamos por medio de líneas punteadas. Con los dos puntos separados espacialmente es suficiente para obtener geométricamente la imagen completa del cuerpo extenso.

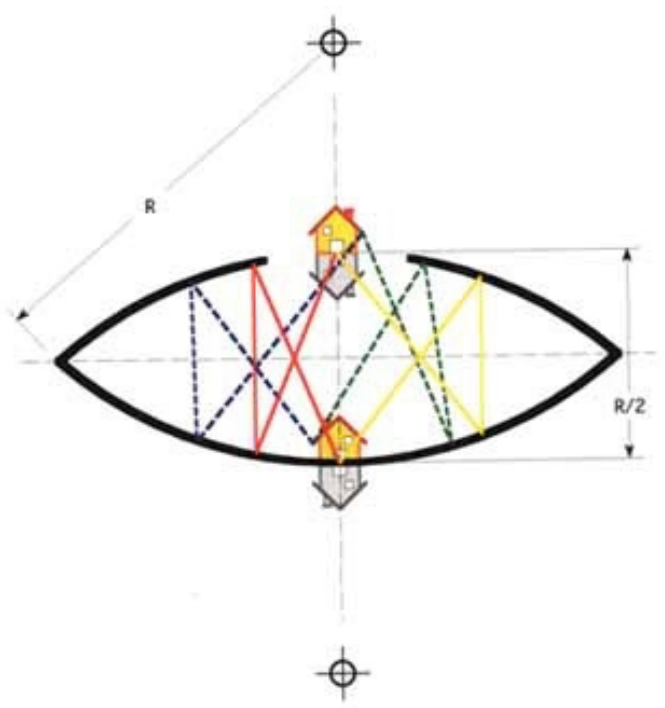

Figura 14. Sistema óptico de dos espejos cóncavos que permiten generar una imagen tridimensional real. La imagen creada corresponde a un PSP de tipo SWG.

Si consideramos la alta velocidad de la luz, dentro del orden de magnitud del sistema, podemos decir que la imagen real observada se forma simultáneamente en todos sus puntos en la salida del sistema óptico, por lo cual estamos en presencia de una imagen con coexistencia óptica, lo que permite calificar específicamente al PSP como de tipo SWG. ${ }^{25}$

A continuación, modelamos causalmente la genealogía óptica de la imagen de la frutilla de la figura 13. En el esquema se muestra entonces tanto la presencia de los procesos causales como de los PSPs involucrados. Además, se puede ver cómo el fenómeno tridimensional complejo se descompone en dos relaciones de superveniencia, en el primer caso de lo pseudocausal a lo causal y en el segundo caso de lo pseudocausal a lo pseudocausal. Esto muestra dos hechos no menores: primero, que lo pseudocausal puede también causar y, segundo, que las relaciones pseudocausales pueden perfectamente ser relaciones de segundo orden y que, pese a esto, los observadores están preparados para admitir que portan alguna forma de realidad física, en la medida que proceden de procesos físicos genuinos. 


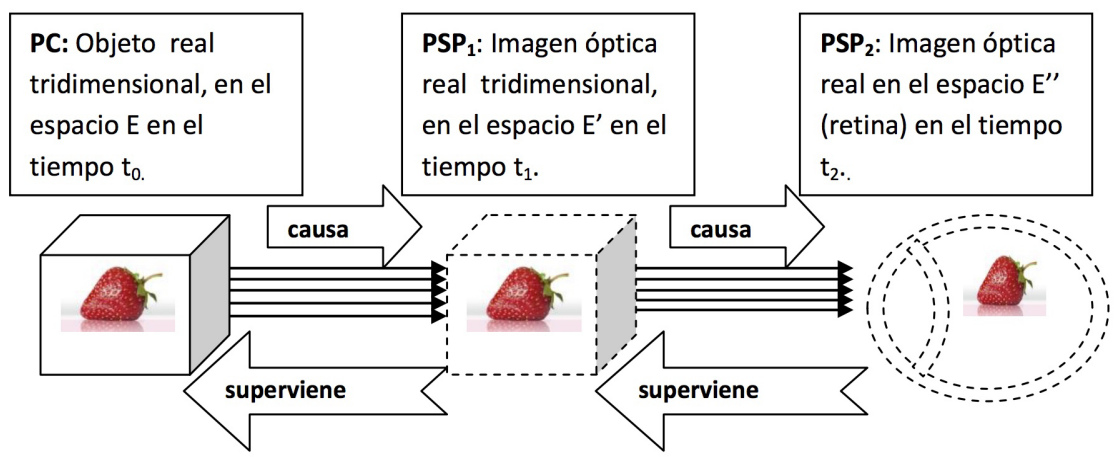

b. Ola de hinchada en el estadio

Por último, queremos ilustrar un tipo de PSP de naturaleza mecánico-óptica que podmos observar recurrentemente en un estadio: el efecto perceptual de ola que puede realizar una hinchada al repletar sus tribunas. Decimos "mecánico-óptica" debido a que la base causal de este PSP es de naturaleza mecánica, aunque el PSP mismo sea, indudablemente, de naturaleza óptica y deba distinguirse de su base causal, ya que su percepción es determinada exclusivamente por la información electromagnética que obtenemos.

En el efecto de ola en un estadio, las personas sincronizadamente interactúan contra el suelo y las bancas para ponerse de pie, levantando sincronizadamente sus brazos, acción que provoca, como sabemos, el efecto perceptual de un movimiento ondulante en la dirección en que la ola, aparentemente, se desplaza. Si la sincronización se realiza de una forma lo suficientemente fina, no sería sorprendente que el movimiento de la ola alcanzara una rapidez mayor que la rapidez de la luz en el vacío, ya que se trata de un movimiento pseudoprosesual, y, por tanto, genera una pseudoentidad que no posee cantidades conservadas, en la dirección del movimiento. 

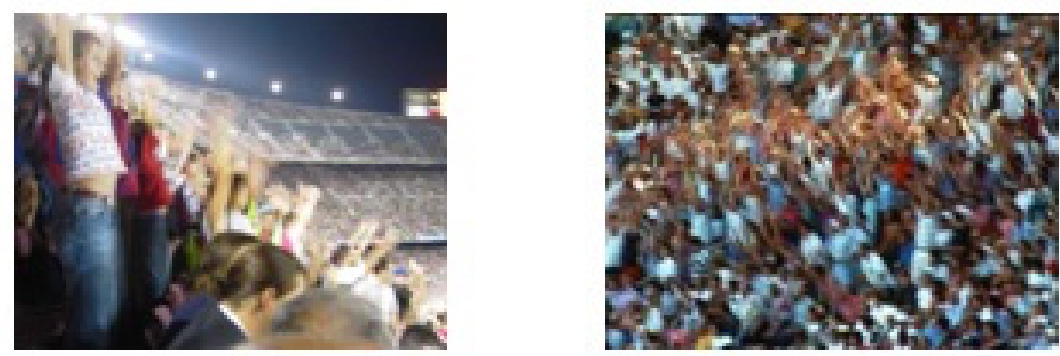

Es posible modelar la mencionada ola de una manera simple si nos ubicamos al frente de algunas de las personas que participan de ella, como se ilustra en la siguiente imagen. Tomemos entonces para nuestro modelo nueve personas similares en un plano frontal, digamos X,Y. Donde Y es la dirección vertical, dirección sobre la cual la persona se moverá ya sea hacia arriba o hacia abajo, y X, la dirección hacia la cual se percibirá el movimiento pseudoprocesual.

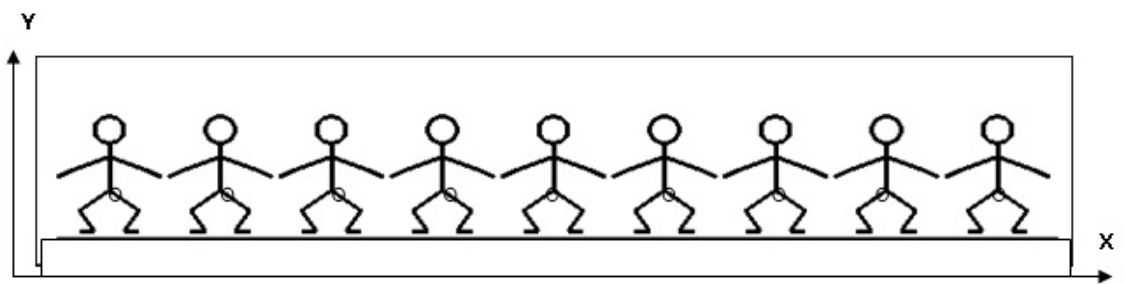

Figura 16. Representación frontal de 9 personas que conforman parte de la hinchada en la tribuna del estadio.

Ahora bien, si representamos a cada una de esas personas como si fuera un punto de centro de masa, podemos graficar dicho punto en un espacio de Minkowski bidimensional, Y,T, de la siguiente forma. 


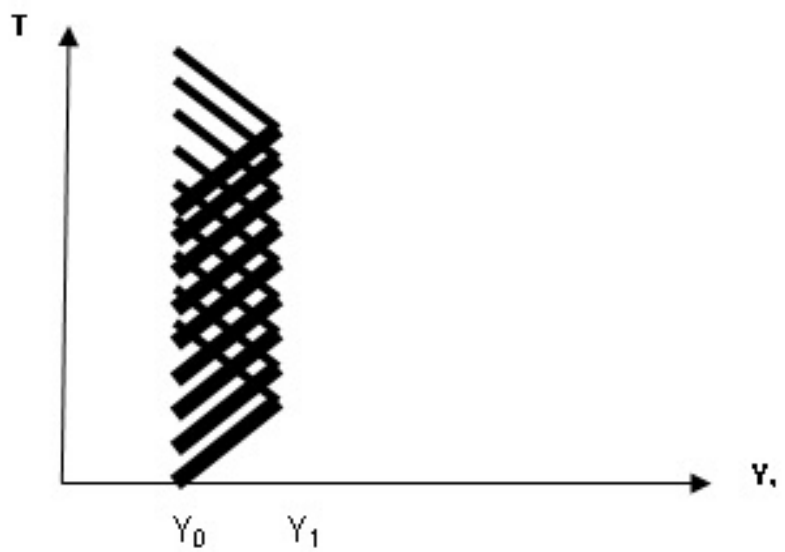

Figura 17. Representación del movimiento del centro de masa de las nueve personas, en un espacio tiempo bidimensional y en la dirección vertical.

Cada persona inicia su movimiento desde su asiento, identificado con la posición $\mathrm{Y}_{0}$, hasta llegar a una altura máxima, $\mathrm{Y}_{1}$, para luego volver hasta $\mathrm{Y}_{0}$. Claramente, cada persona es una entidad física que se mueve continuamente con cantidades conservadas. Por otro lado, cuando la primera persona inicia el movimiento vertical, su vecina casi inmediatamente da inicio también a su movimiento. De ahí que los gráficos de ida y vuelta del movimiento de cada persona aparezcan superpuestos con el gráfico vecino, y así sucesivamente. Por otro lado, si modelamos el mismo conjunto de movimientos, pero esta vez en el plano X,T, obtenemos para la misma secuencia temporal anterior la siguiente representación.

T

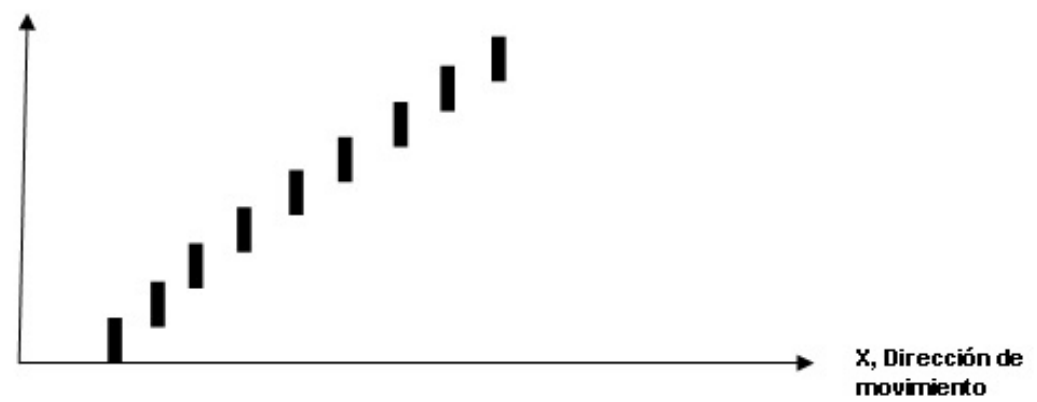

Figura 18. Representación del todo mereológico de las nueve personas, pero observadas en distintos tiempos, con un grado de coexistencia en sus partes temporales. Este es claramente un PSP del tipo TWG. 
Es esta representación la que nos permite apreciar el movimiento aparente en la dirección X y que corresponde a lo que es llamado usualmente el efecto (pseudoprocesual) de la ola de una hinchada. Finalmente, el esquema abajo muestra una modelación simple de las relaciones entre los PCs y los PSPs involucrados en el fenómeno perceptual comentado.

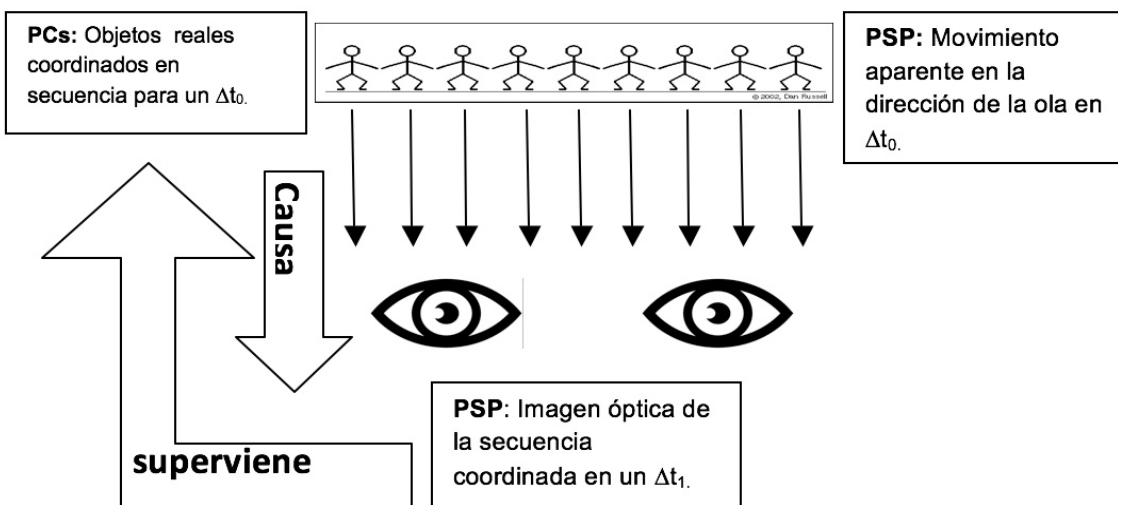

\section{Extendiendo la teoría: líneas y superficies pseudocausales}

Junto con las entidades ya indicadas, en Quezada y Pavez (Quezada y Pavez 2014) hemos introducido, con el propósito de explicar cómo se difunden las relaciones causales entre niveles, los conceptos de líneas y superficies pseudocausales. Las primeras, son PSPs que se forman a partir de posibles interacciones puntuales entre PCs, que se despliegan en una determinada dimensión espacial, como muchos de los casos ya mostrados en las secciones anteriores. Un ejemplo simple puede ser un flujo de luz láser, enviado desde la Tierra, cuyos puntos de interacción con la superficie de la luna se muevan, aparentemente, en una dirección dada. El PSP que forma la línea puede ser sucesivo o simultáneo, pues según lo que hemos venido mostrando, no hay ningún tipo de restricción para ello. Las superficies, son PSPs que se forman debido a interacciones puntuales de PCs que se extienden en dos dimensiones del espacio, y -al igual que las líneas- estas superficies pueden albergar PSPs sucesivos o simultáneos.

Así, desde nuestra perspectiva, la detección de un PC o un PSP (y las mediciones o usos instrumentales asociados a ellos) en un macronivel, presupondrán una relación con PCs o PSPs en un micronivel, mediada por una línea o superficie pseudocausal, que hace de vínculo transicional entre los flujos de PCs, los que proveen la base ontológica. Estos elementos geométricos, por otra parte, no se requieren en la explicación del PC o PSP en el macroni- 
vel, pues ellos no reemplazan a la causación, tal como ésta -de acuerdo a lo dicho anteriormente- se define en la teoría de cantidades conservadas. Los conceptos de línea y superficie pseudocausales, como elementos instrumentales de la teoría ya expuesta, están basados en un conjunto de tesis sobre causalidad ya desarrolladas en el trabajo mencionado anteriormente, por lo que sólo apelaremos a aquellas que resultan directamente relevantes para nuestra argumentación aquí. Estas son las siguientes. ${ }^{26}$

(TG) Los efectos causales medibles y detectables en un nivel superior presuponen siempre una transición desde un nivel inferior mediante una línea o superficie pseudoprocesual como su condición de posibilidad.

(TCE1) Las fases transicionales pseudocausales están determinadas por la dimensionalidad espacial del flujo de procesos: si la fase es en una dimensión es una línea pseudocausal, si en dos es una superficie.

(TCE2) Las líneas o superficies pseudocausales son líneas o superficies de transición pero no de producción causal, esto es, no tienen eficacia causal.

(TCE3) Si lo causal micro/macro y lo pseudocausal micro/macro coinciden en el orden de magnitud, entonces las direcciones espaciales de los procesos involucrados no pueden coincidir.

(TC4) Una superficie pseudocausal en un nivel puede modificar, alterar o agregar direcciones espaciales a los procesos de un nivel distinto para el cual ella es una condición de posibilidad.

En Quezada y Pavez (2014) se formulan además varios ejemplos de causación física en donde estas tesis se aplicarían, entre otros, medición en espectroscopia, medición de la temperatura de un gas, generación de energía eléctrica a partir de energía térmica y -en el caso de un mecanismo cotidiano que incorpora varios principios de física teórica- obtención de efectos pseudocausales a partir del uso de un mouse en un monitor computacional. Por cuestiones de espacio ilustraremos las tesis aquí solamente con un ejemplo de espectroscopia mediante el cual mostraremos cómo un espectro de un elemento atómico en una pantalla se puede interpretar como la presencia de un conjunto de líneas pseudoprocesuales, en las cuales coexiste un conjunto de fotones de idéntica energía (en cada línea) asociada a la transición de niveles de energía $\mathrm{N}$ de los electrones atómicos. 
Con él además pretendemos destacar cómo los fotones individuales con un dado nivel de energía (esto es, PCs individuales) pueden caer en la pantalla sucesiva o simultáneamente, generando un PSP espacialmente unidimensional en cada región del espectro (una línea espectral). Es relevante además destacar aquí el tránsito que impone la interacción causal desde el nivel micro (fotón a fotón) al nivel macro (franja brillante). ${ }^{27}$

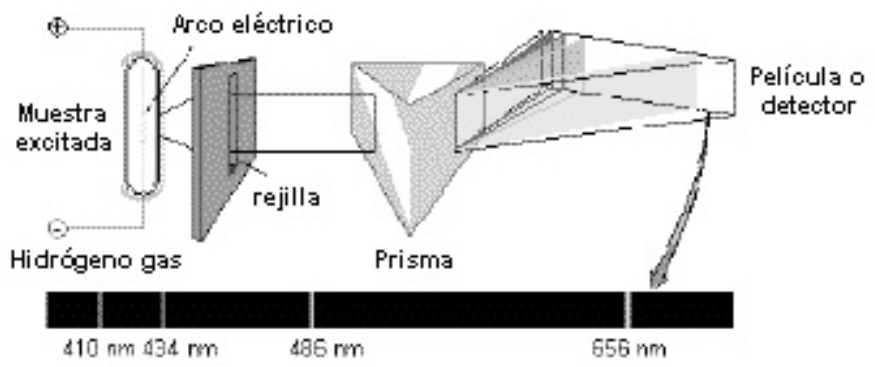

Figura 19. Gas de hidrógeno con electrones excitados que caen al nivel más bajo emitiendo fotones con determinada frecuencia y energía, los que son dispersados por el prisma y detectados por la placa sensible. En el átomo de hidrógeno hay cuatro líneas que son visibles.

Como se observa, el ejemplo ilustra cómo el bombardeo de los fotones de un flujo de luz (PCs lineales en una dirección) es asimilado por la pantalla, la cual transmite uniformemente las interacciones, a su vez, a quien las observa o se graban directamente en la placa fotosensible, la cual registra fenomenológicamente las franjas (PSPs). Así, constatamos que partimos en un nivel micro, esto es, el movimiento de los electrones excitados en cada átomo de un gas y terminamos, vía las líneas pseudoprocesuales, en un nivel macro en el cual observamos la energía característica a cada longitud de onda o frecuencia.

Hay dos cuestiones valiosas a considerar aquí, la primera, como ya indicamos, es que observamos interacción causal física desde el nivel micro (procesos electrónicos en los átomos del gas) al nivel micro (procesos fotónicos que salen de cada átomo) y desde éste a un nivel macro (la formación de la línea del espectro), que resulta, a su vez, ser un indicador de la cantidad de energía que poseen los procesos que la forman. En segundo lugar, observamos que los efectos tanto en el nivel micro como en el nivel macro, están todos sobredeterminados físicamente y que, de hecho, las líneas pseudoprocesuales son la fuente de la sobredeterminación física. ${ }^{28}$ 
Finalmente, es claro que las formas que puedan adquirir tanto líneas de PSPs como superficies de PSPs, estarán determinadas por las formas tridimensionales de los cuerpos sobre los cuales ejercen su eficacia causal. A modo de ilustración, presentamos cuatro formas posibles.
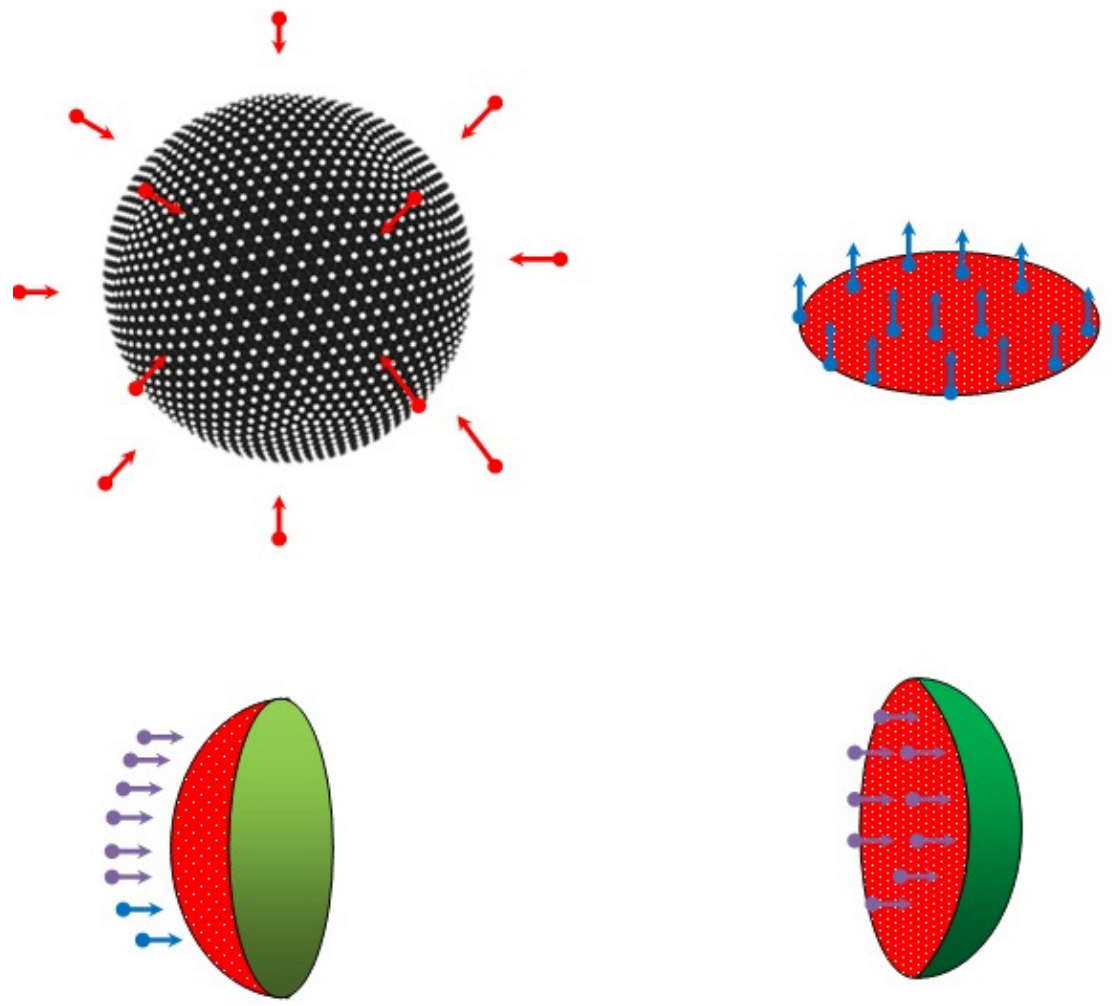

Todas estas superficies pseudocausales pueden servir para modelar múltiples transiciones desde un proceso causal a otro (sea de un nivel a otro diferente o al mismo $)^{29}$. Por ejemplo, la figura superior izquierda, podría representar la capa fina de agua atrapada entre dos capas moleculares tensoactivas que crean una burbuja de jabón, cuya forma esférica es causada por la tensión superficial del agua. La figura superior derecha, podría representar la superficie pseudocausal creada en la base de un pistón como efecto de la presión de las moléculas de agua del vapor creado por una caldera cerrada y que permite convertir energía térmica en energía mecánica cuando aumenta lo suficiente la presión para empujar el pistón. Finalmente, la figura inferior izquierda podría servir -entre muchas posibilidades- para modelar la superficie que se crea cuando un chorro de fotones alcanza la córnea del ojo humano (o si se quiere, el iris), lo que permitirá posteriormente causar una primera información visual en el cristalino. En tanto, la figura inferior derecha, puede corresponder, 
en esta modelación, a la superficie pseudocausal que se crea por la información lumínica recibida del cristalino antes de ser traspasada a las células de la retina y en la que dicha información se transformará en información nerviosa.

Finalmente, cabe enfatizar aquí nuevamente, que efectivamente los PSPs así como las líneas y superficies pseudoprocesuales no causan ni pueden causar en la dirección en que sus constituyentes (PCs) resultan ejercer influencia causal local, sin embargo, según su propia condición de posibilidad, estos constituyentes no pueden exhibir tampoco eficacia causal si no participan de una entidad pseudocausal.

\section{Torretti: causación ordinaria, nomología y antropocentrismo}

Hacia el final de su libro Inventar para Entender, R. Torretti dedica la última sección a tratar de las causas y de las leyes. Él declara allí su compromiso con una concepción antropocéntrica de nuestro "pensamiento causal ordinario" ${ }^{30}$. Torretti dice:

El pensamiento causal ordinario es antropocéntrico y depende del contexto. Cómo distinga efectos y qué identifique como sus causas dependerá en cada caso de los usos y creencias humanas y del propósito que se persiga. (Torretti 2012, p. 540)

Y más enfáticamente,

La experiencia de ser el autor de un hecho -de obrar haciéndolo- es uno de los ingredientes primordiales de la autoconciencia. El filósofo que pretenda no tener idea de ello solo logrará hacer el ridículo. No puede ocultársele que nuestro concepto ordinario de causalidad está íntimamente ligado a esa idea, ya sea porque este se formó como una extensión natural de esa experiencia, ya sea porque..... el concepto de causa funciona de entrada como la categoría más amplia bajo la cual cae nuestro propio obrar en el mundo. (Ibid.)

Junto con esto, Torretti muestra su rechazo a aquella tendencia a considerar que el estudio de la evolución en el tiempo de sistemas físicos mediante procesos gobernados-por-ecuaciones-diferenciales (procesos-GED) "forman una cadena causal en la cual cualesquiera dos estados sucesivos están ligados como causa (el estado anterior) y efecto (el posterior)" (Torretti op.cit., p. 533). Esta asociación explicaría, a su juicio, la "trillada asociación entre causalidad y ley" que nuestro autor deplora. Sólo el estudio de sistemas-GED o procesos-GED puede permitir determinar leyes pues ellas capturan efecti- 
vamente sucesiones o regularidades sujetas a ley. Así, la causalidad da origen a un estudio del pensamiento causal ordinario que -siguiendo los antecedentes etimológicos griegos de la palabra- podemos llamar "etiología" y, por contraste, el estudio de las regularidades mediante procesos-GED, sugiere Torretti, lo podemos llamar "nomología". Ambos modos de pensamiento son fundamentalmente diferentes aunque se pueden conectar en paralelo debido a los intereses y acciones humanas que guían el uso de procesos-GED para representar fragmentos de la realidad, de modo que, para Torretti, ambos "funcionan juntos bastante bien".

Finalmente, Torretti enfatiza que persiste una diferencia fundamental entre la etiología y la nomología. En sus palabras,

La principal discrepancia entre la etiología del pensamiento causal ordinario y la nomología de las ecuaciones diferenciales consiste en que esta presupone continuidad, mientras que aquella depende de la consideración de secuencias de términos discretos (Torretti op. cit., p. 539)

Así, parece haber cuatro tesis que Torretti está dispuesto a defender:

a. El vínculo que ordinariamente reputamos de causación o causalidad debe ser modelado mediante la idea de manipulación o intervención humana. La causación es, por ende, un concepto esencialmente antropocéntrico.

b. El estudio de la evolución de los sistemas físicos en el tiempo se realiza a través de ecuaciones diferenciales. Los procesos físicos así estudiados no representan estudios de la relación causal ordinaria o antropomórfica.

c. El rasgo ontológico fundamental que distingue ambas conceptualizaciones y explica su irreductibilidad metafísica es la oposición continuidad/discontinuidad.

d. El concepto antropomórfico de causación y el no antropomórfico de proceso-GED no pueden estar conectados entre sí pero pueden ponerse a trabajar en conjunto adecuadamente.

Sobre la tesis (a) nuestra perspectiva es de precavida simpatía. En primer lugar, aunque no suscribimos aquí ni en otras partes a una visión derechamente antropomorfista de la causación ordinaria, tampoco excluimos que, en ciertos contextos, un modelo de intervencionismo pudiese integrar PSPs a nivel de dicha causación (sin necesariamente suscribir a una concepción cau- 
sal fisicalista de cantidades conservadas). Esto se deriva de que admitimos en general una concepción más bien pluralista de la definición del vínculo causal, en particular en ámbitos no físicos (cf. nota 24). Pese a esto, es importante indicar aquí que no vemos el modo ni los recursos a los que podría apelar un manipulabilismo antropocéntrico para capturar conceptos como línea o superficie pseudocausal que, a nuestro juicio, están a la base de muchísimas relaciones de causación ordinaria, incluso si se abandonase el procesualismo y se integrasen elementos contrafactuales ${ }^{31}$.

Sobre (b) es importante considerar que en nota introducida en 2012 a la versión en español de Inventar para Entender (nota 65), Torretti sugiere que su concepción de procesos-GED puede encontrar un paralelo adecuado con el concepto de proceso causal de W. Salmon, al que referimos en la primera sección de este ensayo. ${ }^{32}$ Este concepto, tal como lo define Salmon, presuponía el concepto de transmisión de marca y, como se señaló en la misma sección, dicho concepto -motivado por una propuesta de Reichenbach- fue sustituido finalmente por el concepto de posesión de cantidad conservada introducido por Dowe el cual efectivamente permitió superar las muchas dificultades que aquel planteaba. Por ende, cuando Torretti señala en su nota que "los procesos causales en el sentido de Salmon se cuentan entre los candidatos naturales a ser representados científicamente como procesos-GED", deberían entenderse dichos procesos más bien en el sentido Salmon-Dowe, como también se señaló en la mencionada sección. Esta clarificación no es menor pues permitiría mostrar con cierta precisión que, por ejemplo, un proceso de caída libre, un ejemplo que Torretti usa característicamente para representar un proceso-GED, en estricto rigor, terminará siendo descartado como un proceso causal por la teoría original de Salmon, por la sencilla razón que este último requiere autopropagación sin interacciones adicionales. Como deja claro Dowe, procesos como caídas libres u ondas de sonido propagándose en un medio simplemente no pueden ser reales en ausencia de interacciones $\mathrm{y}$, por ello, requieren en su descripción de un campo causal, el que debe implicar tales interacciones (por ejemplo, con sus respectivos campos) ${ }^{33}$. No obstante, los procesos causales definidos de acuerdo a la concepción de Dowe, esto es, de acuerdo a una teoría de posesión de cantidades conservadas, permiten con claridad y sencillez clasificar dichos procesos como genuinamente causales. Hecha esta aclaración y admitida eventualmente la correspondencia entre los procesos-GED y los procesos Salmon-Dowe, lo que restaría es determinar si los primeros podrían calificar también como causales. A esto Torretti replica que es una cuestión más bien de gusto, aunque se inclina por considerarlo un error que restituye la confusión entre la causalidad y la nomología. Por 
nuestra parte, la cuestión relevante no es tanto ésta como la de saber si un proceso-GED se podría conectar con manifestaciones de pseudocausalidad, como las que hemos estudiado aquí. Volveremos sobre esto más adelante.

En relación a (c) nos parecería inevitable coincidir en gran parte con ella si asumiésemos que la casualidad ordinaria de Torretti captura las manifestaciones de entidades pseudocausales de las que hemos hablado en extenso en este trabajo, pues ellas, en su gran mayoría, pueden ser descritas como constituidas de elementos discretos, por oposición a los procesos causales cuyas partes no son, en gran parte, simples secuencias de términos discretos. Como se puede recordar, una condición de definición de la mayoría de las entidades pseudocausales es la separación espacial de sus constituyentes físicos, esto es, procesos causales. No obstante, existen excepciones: no tiene sentido decir, por ejemplo, que una sombra está constituida de términos discretos. Por otro lado, en el caso de los procesos causales tampoco podríamos ser estrictos con el contraste invocado por Torretti pues, como como ha remarcado el mismo Dowe, la teoría de cantidades conservadas, a diferencia de la teoría de Salmon, no está comprometida con la continuidad espacio-temporal de los procesos, lo que abre un ámbito, al menos teórico, a la inclusión de procesos microfísicos en dicha teoría ${ }^{34}$.

Finalmente, todo lo dicho hasta aquí nos lleva naturalmente a concluir que no podríamos aceptar (d), si (i) admitimos que los procesos-GED pueden ser puestos en correspondencia con procesos causales a la Dowe y (ii) que los usos ordinarios y antropomórficos de causación de los cuales habla Torretti pueden asociarse con conceptos y mecanismos pseudocausales, como los que hemos venido desarrollando en este ensayo. Nosotros creemos que hay alguna evidencia para argumentar adicionalmente a favor de (ii) pues es posible mostrar, por ejemplo, que cada vez que decimos que el movimiento del mouse en la mano causa -en un sentido ordinario- el desplazamiento del cursor en la pantalla de un PC, la explicación entera deberá presuponer diferentes elementos y fases pseudoprocesuales a su base ${ }^{35}$. El mismo ejemplo de Torretti sobre la lesión causada al cráneo de un hombre por el golpe de puño de otro puede ser modelado en términos de procesos causales y superficies pseudocausales superviniendo en aquellos ${ }^{36}$. Así, si estas u otras explicaciones de situaciones cotidianas en las que se apela al uso de la causación, tal como la concibe Torretti, son posibles de implementar en términos de nociones causales y pseudocausales, entonces, contra lo que sugiere (d), parecería claro que existe una conexión, explicable con vocabulario físico, entre lo que Torretti considera un proceso físico, describible por una ecuación, y los usos agentivos y antropomórficos del vocablo "causa". Esa conexión mostraría, tal 
vez, no una vía para reducir los usos antropomórficos sino para explicar las bases físicas -mayormente inconscientes- que hacen posible que los agentes racionales perciban y describan una parte -probablemente la más importantede su interacción compleja con el ambiente natural y no-natural en términos causales. Pero esa explicación no puede ser formulada, a su vez, apelando solamente o a conexiones causales o a intereses y motivaciones antropocéntricas, sino a algo más ${ }^{37}$. Y de ese algo más ha tratado este ensayo.

\section{Referencias bibliográficas}

Armstrong, D. (1980) "Identity through Time" en van Inwagen, P. (ed.) Time and Cause, Dordrecht, Reidel.

Dowe, P. (1992) "Wesley Salmon's Process Theory of Causality and the Conserved Quantity Theory", Philosophy of Science 59: 195-216.

Dowe, P. (2000), Physical Causation. Cambridge: Cambridge University Press.

Dowe, P. (2009) "Causal Process Theories" en Beebe, H. et al (eds.) The Oxford Handbook of Causation, Oxford, Oxford University Press.

Gómez, J.M. y Steffen, W. (2009), “Agujeros negros supermasivos”, Investigación y ciencia. vol. 396.

Maudlin, T. (1995), Quantum Non-Locality and Relativity, Oxford, Blackwell.

Pavez, L. y Quezada, W. (2012) "Pseudocausalidad en física", ponencia presentada en el VIII Encuentro de la Asociación de Historia y Filosofía de las Ciencias del Cono Sur (AFHIC), Santiago de Chile.

Quezada, W. (2002), "Causalidad física: procesos causales y cantidades conservadas", Revista de Filosofía, U. de Chile, Vol. LVIII.

Quezada, W. (2013), “LLa causalidad, sólo la causalidad y nada más que la causalidad? Un re-examen de la relación Causal", Conferencia Plenaria, III Congreso Nacional de Filosofía, Valparaíso, Chile.

Quezada, W. y Pavez, L. (2011), “Causalidad, pseudocausalidad y medición”, Revista de Filosofia, U. de Chile, Vol. LXVII. Pp. 251-268.

Quezada, W. y Pavez, L. (2014) "Causalidad y espectralidad: examinando la difusión de lo causal en el mundo" ponencia en XV Jornadas Rolando Chuaqui, Santiago de Chile. 
Reichenbach, H. (1958), The Philosophy of Space and Time, New York, Dover.

Reichenbach, H. (1956), The Direction of Time, Berkeley, University of California Press.

Redhead, M. (1987) Incompleteness, Nonlocality, and Realism: A Prolegomenon to the Philosophy of Quantum Mechanics, Oxford, Clarendon Press.

Salmon, W. (1984), Scientific Explanation and the Causal Structure of the World, Princeton, Princeton University Press.

Schrödinger, E. (1952), “Are there quantum jumps?”, British Journal for the Philosophy of Science, 3 (11), pp. 233-242.

Torretti, R., (2007a), De Eudoxo a Newton, Santiago, Ed. Universidad Diego Portales.

Torretti, R., (2007b), Estudios Filosóficos (1986-2006), Santiago, Ed. Universidad Diego Portales.

Torretti, R., (2012), Inventar para entender, Santiago, Ed. Universidad Diego Portales.

Woodward, J., (2003) Making Things Happen: A Theory of Causal Explanation, Oxford, Oxford University Press.

\section{Notas (Endnotes)}

1 Este trabajo se desarrolló y contó con el apoyo del Proyecto Dicyt-Usach 031253QP.

2 Puede resultar sorprendente, pero la experiencia de los presentes autores sugiere que tales procesos son mediana o escasamente reconocidos por los físicos practicantes.

3 Cf. Reichenbach 1958, pp. 147-149 y p. 204.

4 Desde luego, admitir una ontología procesual presupone que en una descripción ontológica alternativa de la realidad física en términos, por ejemplo, de eventos o sucesos (aquella favorecida clásicamente por la interpretación de Minkowski de la TRE), la formulación del problema de los PSPs se deflaciona a una simple distinción entre secuencias físicas reales e irreales. Por consiguiente, en nuestra aproximación, basada en una ontología de procesos, se asume que el problema de los PSPs no consiste 
simplemente en trazar tal distinción. Esta es, por lo demás, la postura mayoritaria de los autores trabajando actualmente en causalidad física. Para una defensa sistemática de la necesidad de modificar la ontología eventualista de la TRE por una ontología de procesos, cf. Salmon 1984, p. 144.

5 Reichenbach 1956, caps. 2 y 3.

6 Cf. Quezada 2002, para una síntesis y examen más detallado de estas teorías.

7 Una revisión más detallada de estos autores puede encontrarse en Quezada 2002 o en Dowe 2009.

8 Los procesos causales genuinos, por ser temporales, son entidades que se sustentan en intervalos finitos de tiempo y al parecer (aunque Dowe no se refiere explícitamente a esto) de ninguna manera en intervalos diferenciales puesto que, de lo contrario, un proceso finito en el tiempo proyectado al límite, es decir, cuando $\mathrm{Dt}{ }^{\circledR} 0$, podría colapsar en un evento (sin interacción) o en una interacción local. Luego, para Dowe una cantidad conservada -como por ejemplo la energía o la carga- junto a un proceso que evoluciona en un tiempo finito como la cosmolínea de un objeto idéntico, son los ingredientes básicos de las entidades causales.

9 Volveremos sobre el intervalo 0C, denominado tipo espacio o de separación espacial, al tratar en más detalle de los PSPs.

10 Para Dowe la cantidad conservada no necesariamente debe ser constante en todo el proceso.

11 Se debe hacer notar que esta es sólo una definición indirecta de PSP; Dowe parece presuponer que una definición directa no es necesaria si se puede trazar claramente la distinción entre un PC y un PSP.

12 En opinión de Dowe, si no suponemos el criterio de genidentidad no podríamos explicar que mi sombra, por ejemplo, es la sombra mía. Y yo soy un objeto con identidad que evoluciona en el tiempo y persiste; cf. Dowe 2000 p. 105.

13 Dowe 2000 pp. 105-6

14 Quezada 2013 y Pavez y Quezada 2012.

15 Cf. Dowe 2000, cap. 2.

16 Dowe en todo caso reconoce esto, cf. Dowe 2000, p. 105.

17 Cf. Armstrong 1980. Nótese que ya Schrödinger (Schrödinger 1952) ha- 
bía enfatizado la pérdida de identidad en física cuántica, aunque se pueda admitir que el punto permanece abierto al debate.

18 Sobre superveniencia de lo pseudocausal en lo causal cf. Quezada y Pavez 2011.

19 Tampoco, desde luego, nuestra definición (así como la misma definición de Dowe) implica procesos que suponen entidades reales -tachyones por ejemplo- viajando por sobre C. Como advertirá el lector versado en TRE, estos sentidos de no causalidad en TRE corresponden a los que usualmente se distinguen en la literatura del caso y que han sido formulados con bastante precisión por T. Maudlin (cf. Maudlin 1995); cf. también para una discusión relevante del mismo punto Redhead 1987.

20 Ilustraciones tomadas del sitio http://fisica.laguia2000.com/

21 Cf. Gómez y Steffen, 2009, p.36.

22 Para derivar la relación bastará con realizar una operación de diferencia y otra de cuociente. Cf. Gómez y Steffen, 2009.

23 Más detalles sobre los distintos ángulos y velocidades posibles de un chorro galáctico se pueden encontrar en Quezada y Pavez 2011.

24 Desde luego, esto supondría una nueva modificación de lo que cuenta como un PSP. Sin embargo, ya que, por una parte, no excluimos la posibilidad de una reformulación de la relación causal y, por otra, ya que no nos pronunciamos aquí acerca de una superveniencia humeana fisicalista, se puede inferir que no suscribimos ningún compromiso fuerte con un Principio de Clausura Causal de base fisicalista.

25 Las imágenes presentadas, aunque se muestran tridimensionales son siempre imágenes que entran al receptor (un ojo por ejemplo) a través de formas bidimensionales. Incluso si se trabajara con información de imagen holográfica, a partir de luz láser, y donde suponemos la noción de fase de la luz para obtener el efecto tridimensional, la información que recepcionamos a partir de la imagen recreada viene a nosotros por medio de superficies ópticas pseudocausales.

26 TG corresponde a "tesis general" y TCE a "tesis de causación especial". Algunas de las tesis restantes son las siguientes (TCI corresponde a "tesis de causación interniveles", cf. Quezada y Pavez 2014):

TCI1 Lo pseudocausal superviene directa o indirectamente en lo causal. 
TCI2 Si lo pseudocausal superviene en lo causal, es imposible que lo primero esté en un nivel micro y lo segundo en un nivel macro.

TCI3 Lo causal micro causa en un nivel micro o macro.

TCI4 Lo causal macro puede causar en el nivel micro.

27 Este ejemplo muestra una transición de un nivel (micro) a otro (macro) por medio de un PSP generado por procesos efectivos. Incluso, los autores, han estado incursionando en rescatar procesos causales en el micromundo, con resultados ya expuestos en congreso de ciencia y filosofía. Por otra parte, también es importante indicar que en este tipo de mediciones espectrales, se puede obtener no sólo espectros de emisión, sino también los denominados espectros de absorción, donde los PSPs formados se construyen por ausencia de interacciones, es decir por medio de PSPs de tipo sombra.

28 Obviamente con la expresión "sobredeterminación" no estamos aludiendo necesariamente a un compromiso con el determinismo metafísico, esto es, los efectos desencadenados por la sobredeterminación no deben verse necesariamente como instancias de una ley universal o regularidad cobertora.

29 Los cuadrados o los puntos en ellas son obviamente idealizaciones representando PCs puntuales. Las flechas destacadas indican la dirección relevante de dichos procesos en la superficie o en su entorno en orden a obtener los efectos característicos.

30 Torretti ha expresado directamente la misma opinión en Torretti 2007b, pp.213-220, a propósito de un comentario a Woodward 2003.

31 Indicamos esto debido a que las visiones clásicas de manipulabilismo causal de base antropomórfica han sido normalmente criticadas, sobre todo cuando se modelan procesos o estados físicos imaginablemente inaccesibles a cualquier conceptualización por manipulación directa. Empero, las versiones más contemporáneas del tipo de las desarrolladas por Woodward y otros parecen resistir adecuadamente muchas de esas críticas al introducir, desde el punto de vista formal, herramientas estadísticas y, desde el punto de vista filosófico, nociones contrafactuales. Así, es posible modelar en su interior conceptos como el de manipulación posible. Torretti ha expresado claramente su cercanía a estas concepciones, sobre todo en relación al pragmatismo que de ellas deriva y que parece capturar mejor su idea de causación ordinaria; cf. Torretti, Ibid. p. 215.

32 Torretti desecha la posibilidad de postular otro eventual paralelo entre su 
concepto de causación ordinaria y el concepto de interacción causal, tal como lo definía Salmon.

33 Dowe 2000, pp. 74-5.

34 Dowe 1992, p. 214.

35 Hemos mostrado cómo implementar esta explicación en Quezada y Pavez 2014.

36 Cf. Torreti 2012, p. 538

37 Torretti sugiere una explicación antropocéntrica de cómo, por consideraciones pragmáticas, se puede elegir un modelo -GED para representar fragmentos de una realidad acotada, por ejemplo, acciones que llevan de un input a un output computacional o la elección e implementación de experimentos para explicar fenómenos naturales (cf. Ibid, p. 541). Desde luego, nuestra propuesta va en otra dirección, aunque puede interactuar con la explicación de Torretti. 